Cashell, K.A., Malaska, M., Khan, M., Alanen, M., Mela, K. Experimental and numerical analysis of stainless steel cellular beams in fire. Fire Safety Journal, 121. pp. 103277 - 103277. ISSN: 0379-7112. Accessed here:

https://www.sciencedirect.com/science/article/pii/S0379711221000047

\title{
Experimental and numerical analysis of stainless steel cellular beams in fire
}

Katherine A. Cashell ${ }^{a^{*}}$, Mikko Malaska ${ }^{\mathrm{b}}$, Mustesin Khan ${ }^{\mathrm{c}}$, Mika Alanen $^{\mathrm{b}}$, and Kristo Mela ${ }^{\mathrm{b}}$

aarunel University London, Kingston Lane, Uxbridge, UB83PH. katherine.cashell@brunel.ac.uk

'⿳亠口冋口十 Tampere University, P.O. Box 600, FI-33014 Tampere University, Finland.

mikko.malaska@tuni.fi

${ }^{c}$ Hong Kong Polytechnic University, Mustesin.khan@polyu.edu.hk

\section{Highlights:}

- Details of fire test on a stainless steel cellular beam

- Development and validation of FE model

- Study into the most salient parameters

- Advantages of stainless steel in fire, compared with carbon steel, presented.

\begin{abstract}
:
This paper presents the details and analysis of a fire test conducted on a stainless steel cellular beam, as well as the development of a finite element model to further study the behavior. Cellular beams are increasingly popular in the construction as they provide a structurally and materially efficient design solution as well as allowing the passage of services. Their behavior in fire can be challenging as the web-post typically reaches higher temperatures than equivalent webs in solid beams. Stainless steel is also increasingly popular for structural applications, mainly due to its excellent corrosion resistance, as well as its other attractive physical and mechanical attributes. The focus in this paper is on the behavior of stainless steel cellular beams, which combine the attractive qualities of stainless steel with the structural efficiency of beams with openings, in fire. A fire test has been conducted which is described and discussed. Then, a finite element analysis model is developed to analyze the thermo-mechanical behavior of unprotected stainless steel cellular beams. The model is validated using the experimental results and then employed to investigate the important parameters which influence the behavior.
\end{abstract}

Keywords: cellular beams; structural response; modeling; finite element analysis; stainless steel; fire test. 


\section{Introduction}

Steel beams with web openings such as cellular beams are commonly employed in framed structures to facilitate lightweight buildings and long spans, thereby allowing large column-free internal spaces, a high degree of flexibility in service routing and reduced floor-to-floor height. Cellular beams are regular I-shaped girders which have circular openings in the web along the length of the member. They are typically made in one of two ways. Firstly, they can be produced by cutting the rolled steel sections longitudinally and then re-welding the two portions together to create a deeper beam with a series of circular holes [1]. The other method is to fabricate the member by welding plates together into the desired shape, much like a plate girder. Using this approach, the flange and web dimensions can be selected to be the most efficient for the applied loading, form of construction and opening requirements. However, these types of bespoke beams may come at a higher cost. There are a number of ways that cellular beams can fail, but the most typical modes are either web-post buckling or Vierendeel bending, associated with buckling of the web-posts [2].

With the growing interest in cellular beams in recent years, there has also been some research effort directed towards the behavior in fire. In this scenario, it has been shown that the temperature of the web-post in a cellular beam increases at a faster rate compared to an equivalent solid beam. This then results in greater requirements in terms of passive fire protection [3], which is a significant disadvantage to using cellular beams in many applications where relatively long periods of fire resistance are required. A reduction or even elimination in the need of this protection would offer substantial economic incentives including lower construction and maintenance costs, and a shorter construction period. There are a number of different strategies for removing the requirement for passive fire protection, and one of these is to use alternative materials to carbon steel, which perform better in a fire, such as structural stainless steel. However, there is little information available on the performance or design of stainless steel cellular beams.

Stainless steel is a very versatile structural material, which has seen a large growth in usage particularly in load-bearing construction applications, in recent years. There are many different grades of stainless steel, and these are typically categorized into five different families, according to their metallurgical composition [14]. These include the austenitic, ferritic, duplex, martensitic and precipitation hardened grades. The austenitic and duplex grades are most common in structural applications and they comprise $17-18 \%$ and $22-23 \%$ chromium, respectively. Stainless steel is well known for its corrosion resistance, and this is perhaps the property which first led to it being considered and used in structural engineering. However, more recently, as researchers have investigated the behavior of stainless steel structures in more detail, many other significant advantages have also been discovered including excellent mechanical properties, low maintenance requirements, long life-cycle, good formability and full recyclability [14]. Stainless steel offers excellent ductility and strain hardening capacity compared with traditional carbon steel, which is particularly desirable in design as a ductile section provides warning of imminent collapse. 
In addition to these properties, stainless steel offers better fire behavior compared with carbon steel, in terms of the mechanical and physical properties [4]. The strength and stiffness of the material degrades at a significantly slower rate compared with carbon steel. For example, Fig. 1 presents the reduction in the elastic modulus (E) for grade 1.4301 austenitic stainless steel and carbon steel with increasing temperature, according to Eurocode 3 Part 1-2 [5]. This graph is presented in terms of the reduction factor $\left(\mathrm{k}_{\mathrm{E}, \theta}\right)$, which is determined as the ratio of the elastic modulus at a given temperature $\left(\mathrm{E}_{\theta}\right)$ and the equivalent value at ambient temperature $(\mathrm{E})$, versus temperature. It is clear that in the critical range for steel structural members, which is between $400^{\circ} \mathrm{C}$ and $800^{\circ} \mathrm{C}$, stainless steel retains a much higher proportion of its stiffness which can have a major influence on failure of the member under fire conditions.

Previous research has shown that the convective heat transfer coefficient and emissivity values of structural stainless steel members exposed to fire are significantly better than those for carbon steel members [6]. The specific properties vary for different grades of stainless steel, depending on the constituent elements of the alloy, and therefore it is important to select the appropriate grade for each application. There have been limited fire tests in the literature on structural stainless steel flexural members [e.g. 4, 16] and these have given a valuable insight into the key behavioral characteristics. The load ratio and section height have been found to be particularly influential in terms of the critical temperature and fire resistance of stainless steel beams in fire [16]. Nevertheless, there have hitherto been no tests conducted on stainless steel cellular beams, in the available literature.

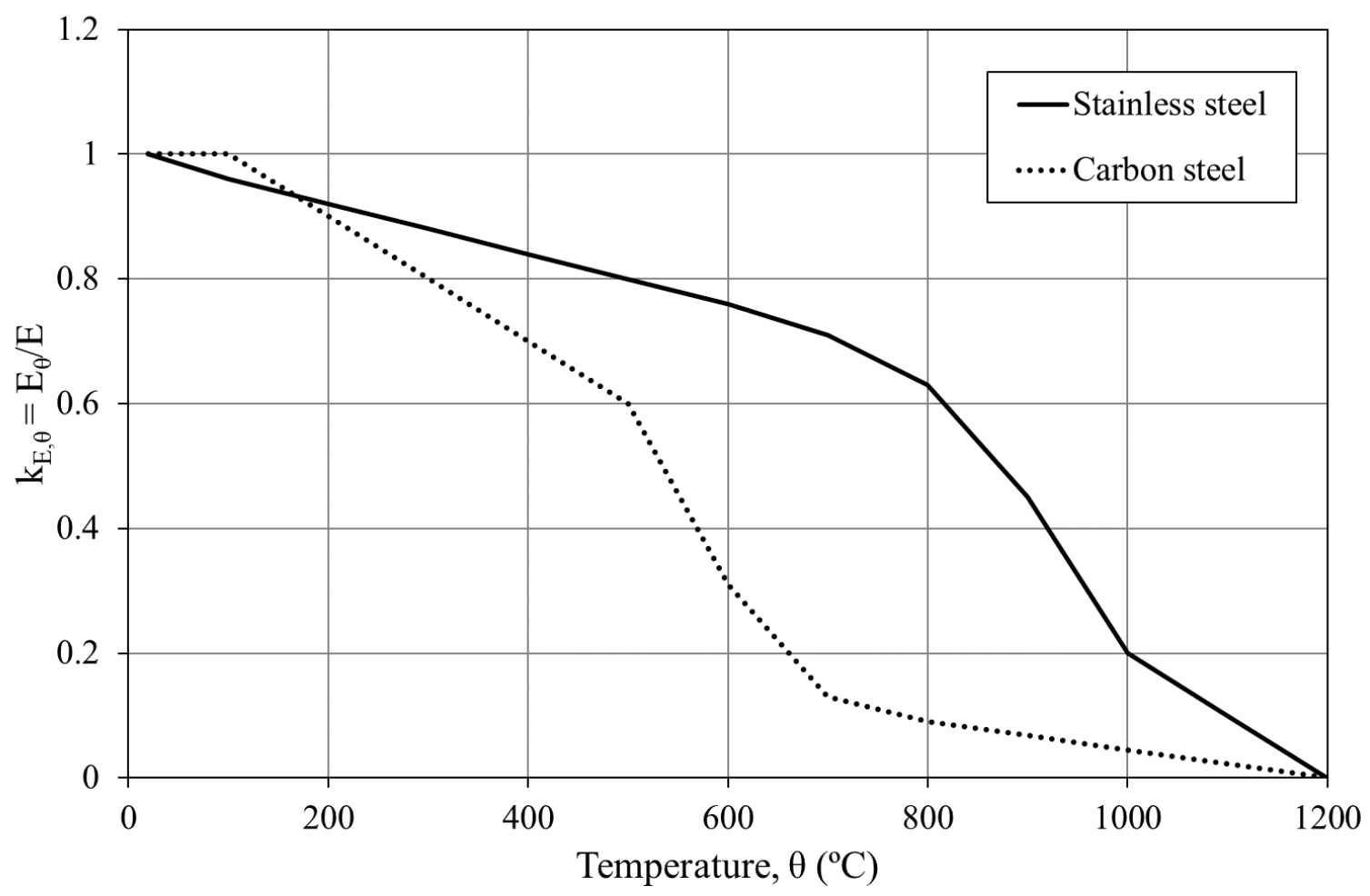

Fig. 1 Stiffness retention for stainless steel and carbon steel at elevated temperatures 
It is important to recognize that stainless steel is significantly more expensive than carbon steel in terms of initial cost, but with careful and efficient design, as well as accounting for the wholelife costs, it can provide a competitive solution. Moreover, for all grades typically used in structural applications, the favorable mechanical and physical properties compared with carbon steel at elevated temperature may result in stainless steel members achieving greater fire resistance even for unprotected elements, thus reducing or even removing the requirements for passive fire protection. The current work aims to investigate this possibility for stainless steel cellular beams and proceeds with a detailed description of the fire test followed by the numerical analysis.

\section{Fire test}

This section will describe the fire test which was conducted on a stainless steel cellular beam at the Fire Laboratory of Tampere University in collaboration with Brunel University London. The aim of the test was to investigate the performance of these members in fire conditions and to provide data for the validation of finite element analysis simulations, which will be presented later. The test was designed to investigate beam deflections, the fire resistance in minutes, the failure mode and the temperature profile and gradient, through the depth of the cellular beam.

\subsection{Test specimen and arrangement}

The experimental research was conducted in accordance with European test standards for loadbearing beams SFS-EN 1365- 3 [7] and for general fire resistance test requirements EN 1363-1 [8]. In accidental building fires, conditions vary depending on fire load and compartment characteristics. Therefore, test conditions were chosen from general fire resistance tests standards that are used to classify loadbearing structures. The beam was fabricated from plates in grade 1.4301 austenitic stainless steel and was provided by Stalatube Oy Finland. A series of tensile tests were conducted in order to obtain the constitutive relationship of the material, comprising at least three tests from material in both the web and the flange; the results are presented in Fig. 2. 


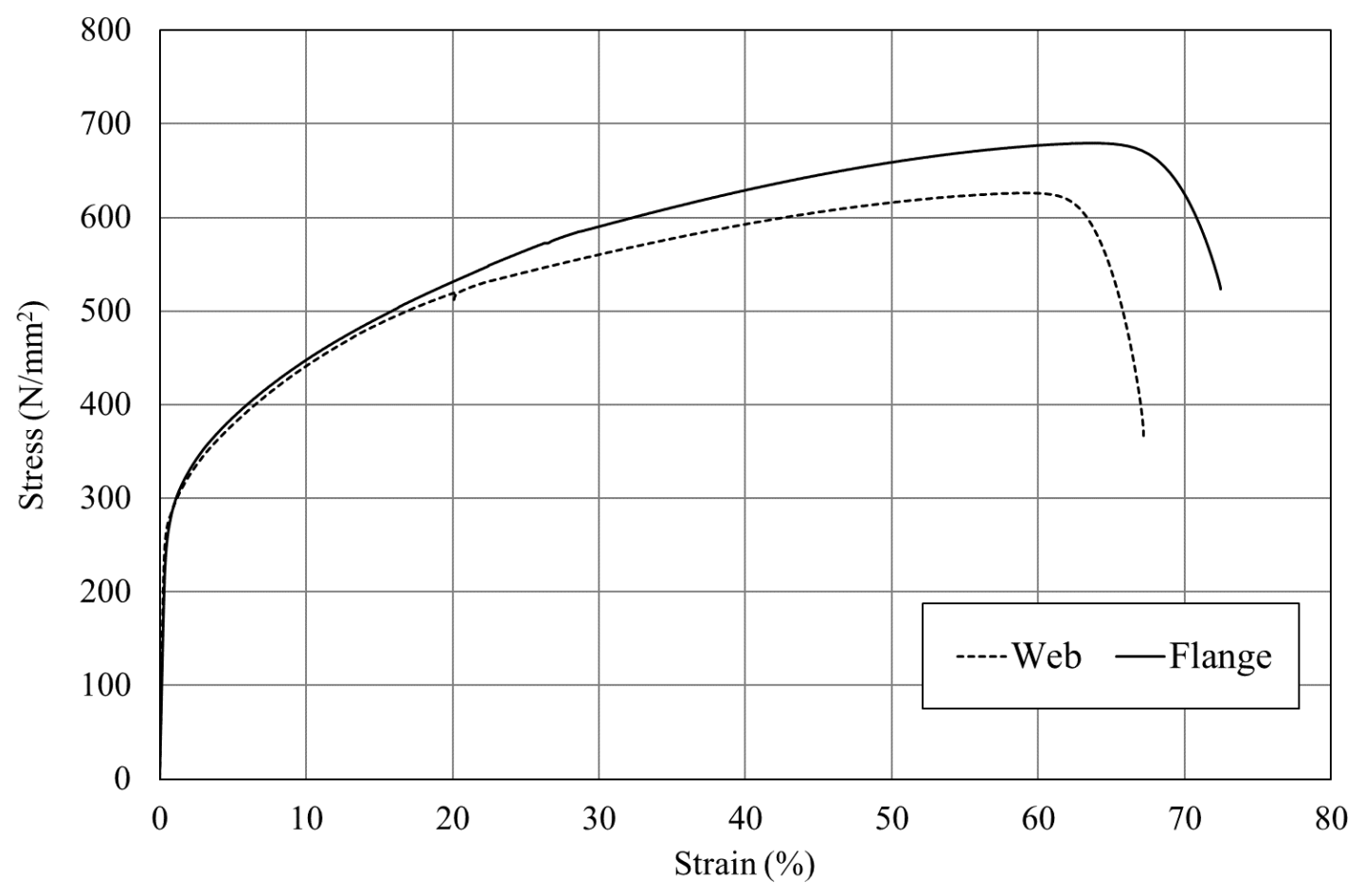

Fig. 2 Stress-strain response of the austenitic stainless steel material used in the test beam

The beam was installed across the longer span of the $3000 \mathrm{~mm} \times 4000 \mathrm{~mm}$ furnace chamber. The total length and span of the beam were $5000 \mathrm{~mm}$ and $4300 \mathrm{~mm}$, respectively, and the length exposed to fire was $4000 \mathrm{~mm}$. It has an overall depth of $290 \mathrm{~mm}$ and the width of the flanges was $300 \mathrm{~mm}$. The beam flange and web thicknesses were $14 \mathrm{~mm}$ and $8 \mathrm{~mm}$, respectively, and the size of the web to flange welds were $5 \mathrm{~mm}$. The design of the beam included $8 \mathrm{~mm}$ thick web stiffeners located at the beam supports and at the load application points on both sides of the web to avoid any local effects in these regions. The diameter of circular openings were $200 \mathrm{~mm}$ and they were located at $300 \mathrm{~mm}$ centers. A schematic of the beam and opening geometry is presented in Fig. 3 including the (a) front and (b) side elevation (all units are in $\mathrm{mm}$ in these schematics). 


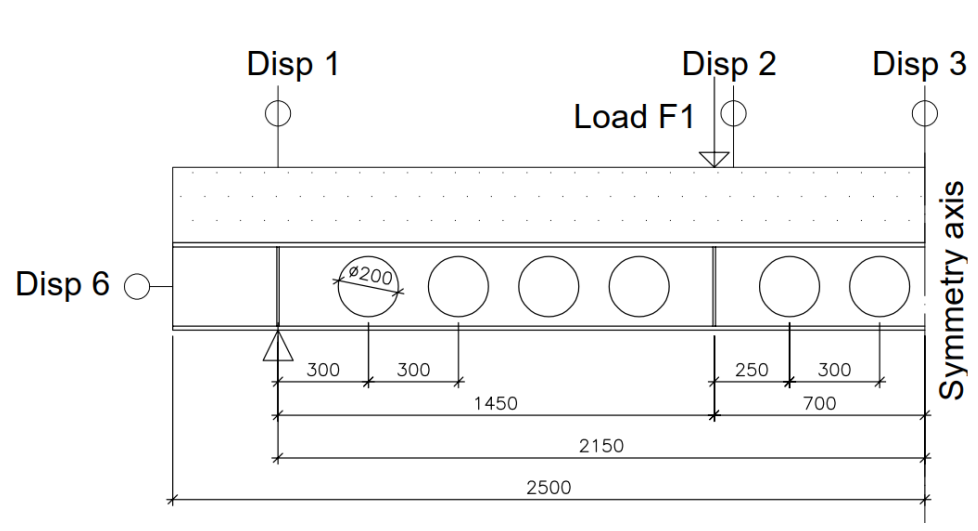

(a)

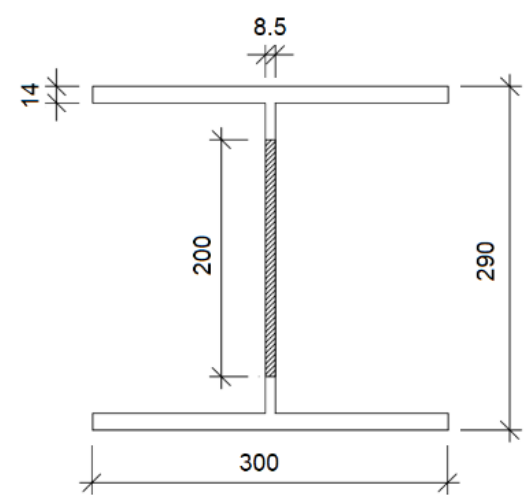

(b)

Fig. 3 Schematic view of (a) half the test specimen and (b) the elevation (all dimensions are in $\mathrm{mm})$

\subsection{Loading and support conditions}

The beam was simply supported with one end placed on a roller support. It was loaded in a fourpoint loading arrangement whereby two concentrated loads of $58 \mathrm{kN}$ each were applied on the top flange of the beam (as indicated by Load F1 in Fig. 3). These loads were applied through hydraulic jacks fixed to a load application frame above the test furnace, as shown in Fig. 4(a). The test load was determined to be around $30 \%$ of the ultimate load found from pre-design calculations made at ambient conditions. In addition, concrete blocks were placed on the upper flange of the beam in order to simulate the floor slab and to provide three sided heating. It is noteworthy that in a real building application, the floor slab would most likely be connected to the beam using shear connectors, but this is not included in the current test in order to keep the set-up as simple as possible, and focus on the behavior of the cellular beam. The $1200 \mathrm{~mm}$ long blocks were installed with their longer dimension perpendicular to the beam span, as shown in Fig. 4(b). The self-weight of these blocks bearing on the beam was approximately $1.5 \mathrm{kN} / \mathrm{m}$. As the concrete blocks bearing on the beam top flange were relatively light, friction between the blocks and beam could not be relied upon to guarantee lateral restraint. The remaining area of the furnace chamber was covered with aerated concrete elements spanning parallel to the steel beam. The beam was not fire protected as the intention was to understand the fire performance of the bare stainless steel beam. It was continuously loaded to the test load for over an hour before the elevated temperature loading was applied through ignition of the furnace. The fire load was applied in accordance with the standard ISO 834 fire curve, described in EN 1363-1 [8] and the fire test was performed in accordance with EN 1365-3 [7]. 


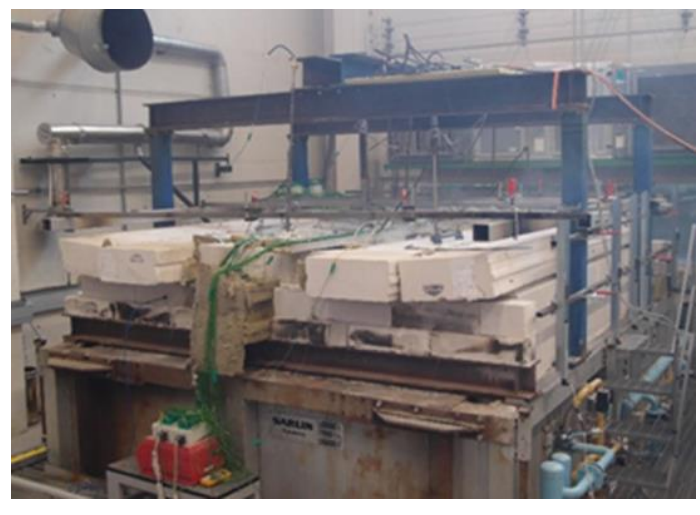

(a)

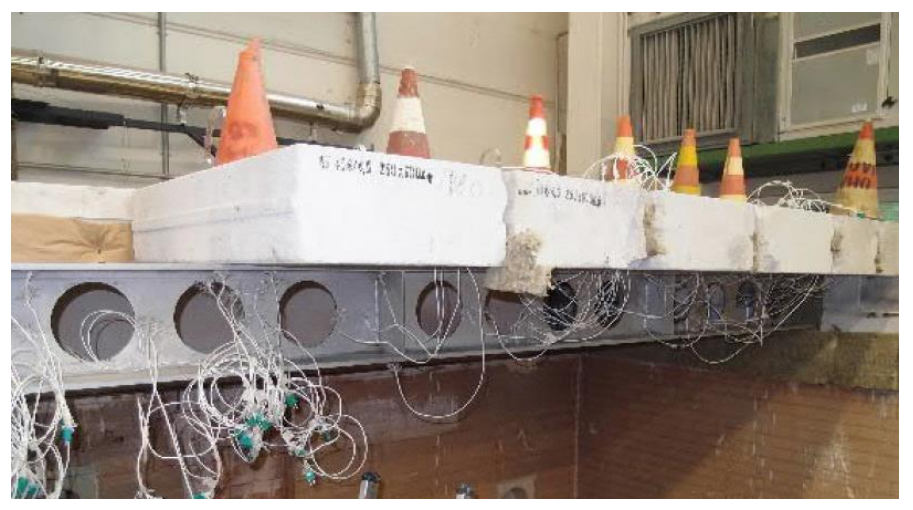

(b)

Fig. 4 Images from the test including (a) the loading arrangement above the furnace, and (b) the specimen before testing, including the concrete blocks on the top flange.

\subsection{Instrumentation}

The furnace temperature was measured using 8 plate thermometers, in accordance with EN 1363-1 [8]. The temperature distribution in the cellular beam was measured using 70 thermocouples, which were installed at various locations along the beam span. K20-2-350 Ktype thermocouple wires were installed in pre-drilled holes in the steel section. Fig. 5 shows the thermocouple locations at the beam mid-span, for example. The vertical beam deflections and axial displacements were recorded using six linear differential transducers connected to the specimen through steel wire ropes (these are evident in Fig. 3, denoted as Disp 1, Disp 2, etc.). Deflections were measured at the mid-span and also at the load application points.
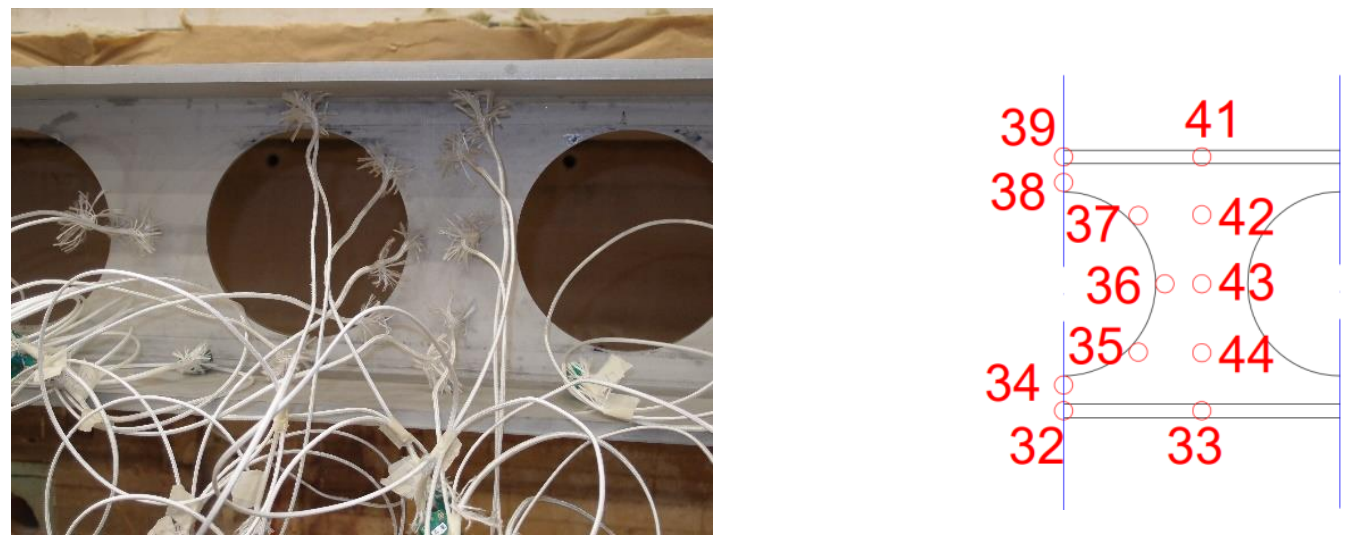

Fig. 5 Locations of the thermocouples in the beam at the mid-span. 


\subsection{Test results}

The performance criteria for the beam load-bearing capacity is defined using the limiting values from EN 1363-1 [8]. Load-bearing capacity is lost when either of the limiting value of deflection or the limiting rate of deflection is exceeded. This standard employs a maximum deflection limit of $\mathrm{L}^{2} / 400 \mathrm{~d}$ and a maximum deflection rate of $\mathrm{L}^{2} / 9000 \mathrm{~d}$, respectively, where $\mathrm{L}$ is the span of the beam and $\mathrm{d}$ is the overall depth of the section. Using these formulae, the limiting value for deflections is $159 \mathrm{~mm}$ and the limiting rate of deflection is $7.1 \mathrm{~mm} / \mathrm{min}$. In the current test, the second criterion referring to the rate of deflection was the critical case. The measurements taken during the tests are presented in Fig. 6(a) for the vertical deflections and Fig. 6(b) for the rate of increase of vertical deflections, at the mid-span, with increasing temperature.

It is shown that in terms of the mid-span vertical deflections, the beam responded linearly until about 24 minutes by which time the furnace temperature had risen to over $800{ }^{\circ} \mathrm{C}$. After this point, the rate of deflection began to gradually increase due to the deterioration of the beam mechanical properties. After about 27 minutes, the rate of deflection started to increase and the limiting value for this criterion was exceeded around 28 minutes after ignition. At that time, the beam had deflected $65 \mathrm{~mm}$ and the furnace temperature was around $840{ }^{\circ} \mathrm{C}$. The rate of beam deflection started to increase rapidly 34 minutes after ignition and the burners were shut off 36 minutes after ignition when the maximum beam deflection exceeded the limiting value of $159 \mathrm{~mm}$. The maximum deflection occurred at the load application point.

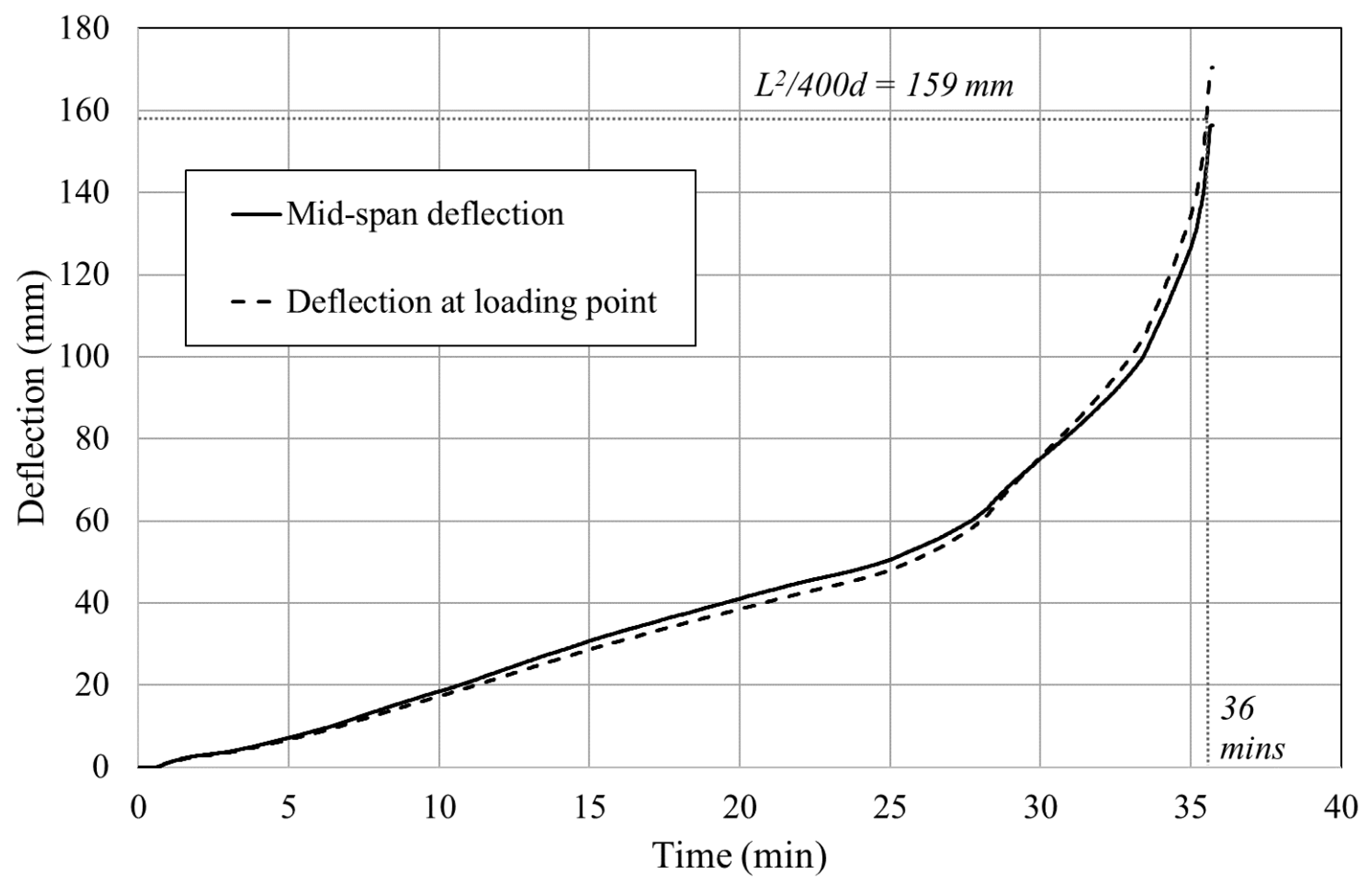

(a) 


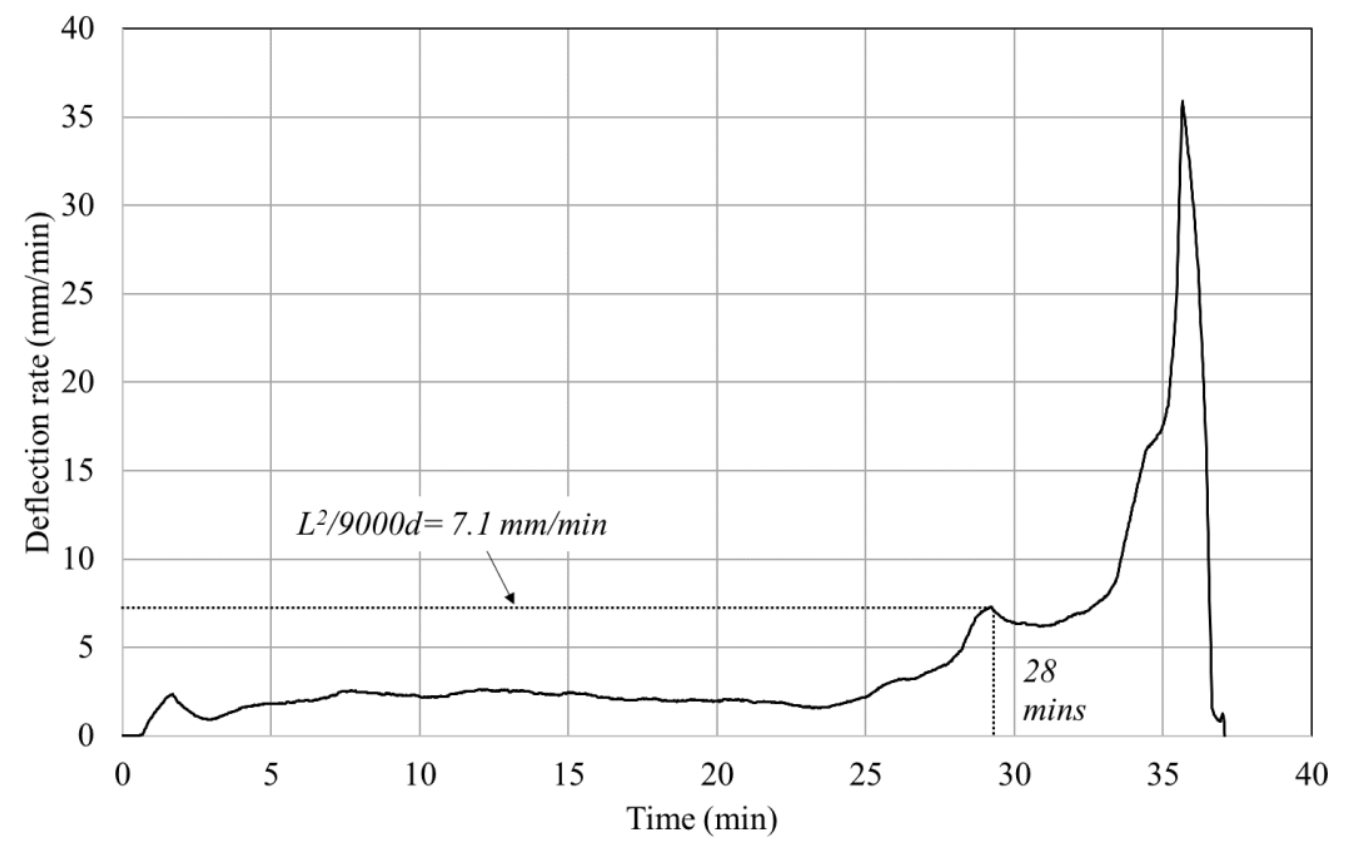

(b)

Fig. 6 Test results in terms of (a) vertical beam deflections versus time and (b) rate of midspan deflection with time.

The testing standard EN 1363-1 [8] and the fire resistance classification standard EN 13501-2 [9] give two different assessments for the beam loadbearing capacity. The first standard states that the capacity is reached as soon as one of the two criteria is exceeded as discussed before, which in this test gives a fire resistance classification of R20. In accordance with the classification standard, failure to support the load is deemed to have occurred when both of the criteria have been exceeded, leading to classification R30 in this test. The furnace temperature and the stainless steel temperature development at mid-span is shown in Fig. 7, for (a) the cross-section of the beam and (b) the web. The corresponding thermocouple locations are shown in Fig. 5. At failure $\left(28 \mathrm{~min}\right.$ ), the stainless steel temperatures at beam mid-span varied between $529{ }^{\circ} \mathrm{C}$ and $785^{\circ} \mathrm{C}$ and the maximum temperatures were recorded in the web. The difference between bottom and top flange temperatures was about $250{ }^{\circ} \mathrm{C}$, mainly owing to the presence of the concrete blocks on the top flange. Similar temperature development was recorded in all beam sections. At 36 minutes, the stainless steel temperatures at mid-span varied between $632{ }^{\circ} \mathrm{C}$ (top flange) and $834^{\circ} \mathrm{C}$ (bottom flange and web). 


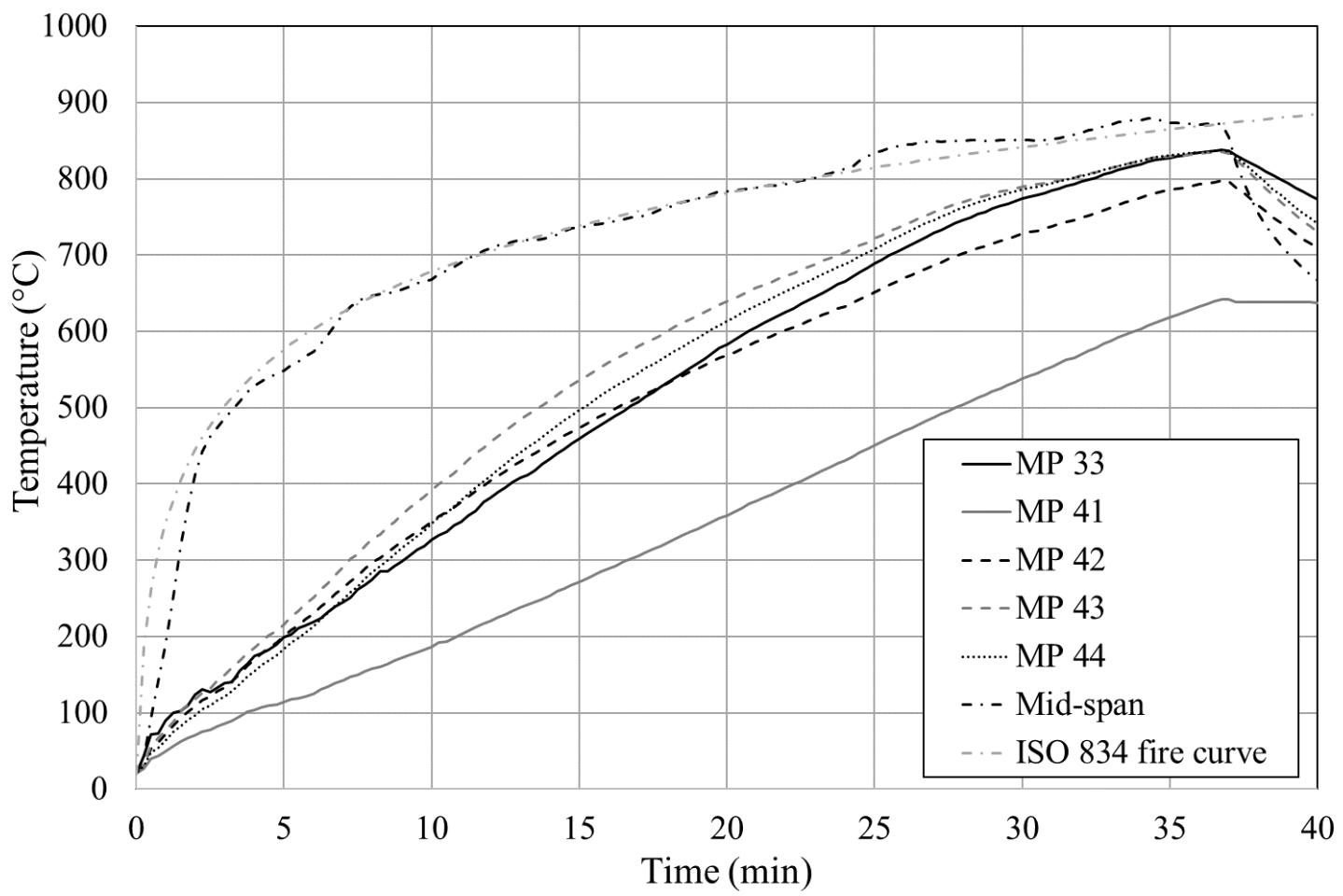

(a)

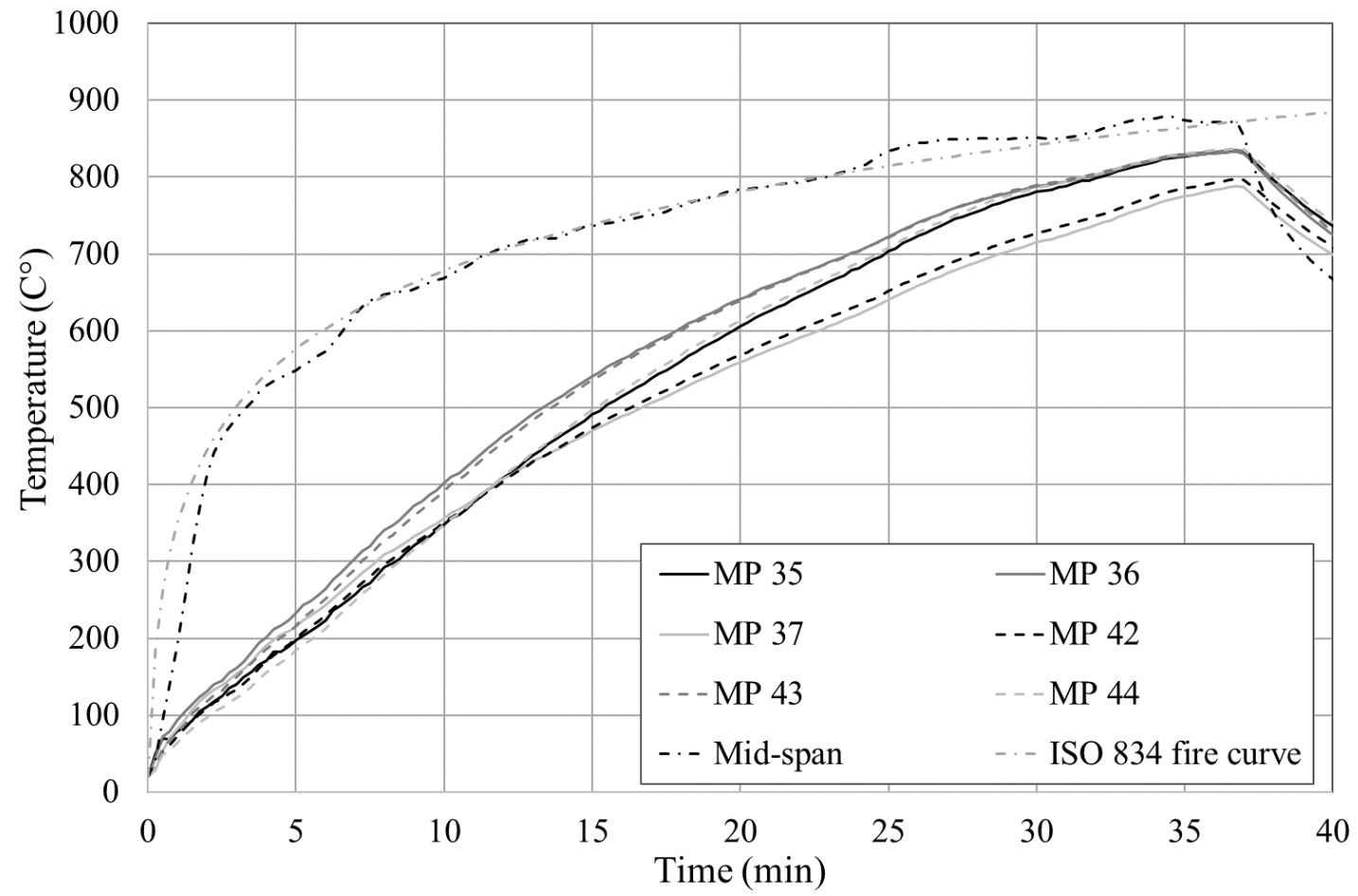

(b)

Fig. 7 Development of the stainless steel temperatures at mid-span (a) over the beam crosssection and (b) in the web. 


\subsection{Failure mechanism}

The failure mechanism of the beam was buckling of the web-posts between the load application point and the beam support. No lateral instability of the beam was observed during testing. Fig. 8(a) shows the deflected shape of the beam after testing while Fig. 8(b) presents the failure mode forming an S-shape in the web between openings. The failure mode observed during the test appeared to be mainly web post buckling due to shear. It is possible that some Vierendeel bending action also occurred owing to the combination of shear and bending at the openings, although this was not clearly observed. As described previously, the beam responded linearly until about $24 \mathrm{~min}$ at which point the maximum and average beam web temperatures were 703 ${ }^{\circ} \mathrm{C}$ and $672{ }^{\circ} \mathrm{C}$, respectively. Failure occurred around 5 minutes later when the maximum web temperature had increased to $785^{\circ} \mathrm{C}$ and the average web temperature was $759{ }^{\circ} \mathrm{C}$. At this average temperature, Youngs modulus and the material strength $\left(\mathrm{f}_{2, \theta}\right)$ are reduced to $66 \%$ and $43 \%$, respectively, of their value at $20^{\circ} \mathrm{C}$ [5]. For carbon steel at $759{ }^{\circ} \mathrm{C}$, the corresponding reduction factors are significantly lower being $16 \%$ and $11 \%$ for the effective yield strength and the slope of the linear elastic range, respectively [5].

The above results clearly demonstrate the favourable performance of the stainless steel cellular beam relative to a carbon steel equivalent. Obviously, there are some factors which would be different if a similar test was conducted on an identical member made from carbon steel (e.g. different temperature profiles) but nevertheless, the results of this test demonstrate that cellular beams made from austenitic stainless steel perform very well in a fire condition.

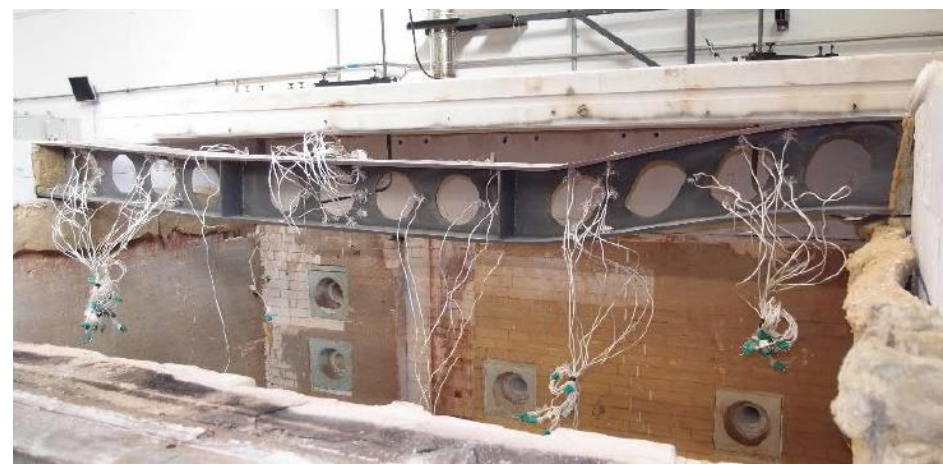

(a)

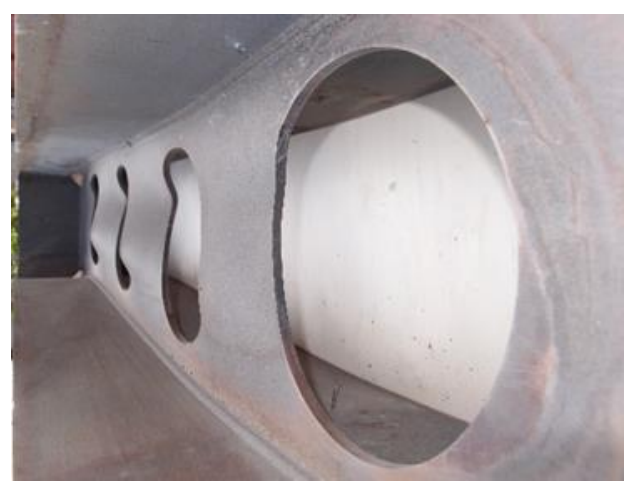

(b)

Fig. 8 Images from the test specimen after testing including views of (a) the full member and

\section{Numerical modeling}

(b) web-post buckling.

A finite element (FE) analysis model has been developed to understand the behavior of stainless steel cellular beams in fire, and to investigate the influence of key parameters. The finite element software package Abaqus is employed to model the stainless steel cellular beam. The details of the cellular beam which are employed in the model are based on the fire test which was presented in the preceding section. 


\subsection{General details of the model}

The cellular beam is modelled using shell elements (called S4R) which are available in the Abaqus library [10]. These have four corner nodes, each with six degrees of freedom, and are suitable for thick or thin shell applications. A mesh convergence study has been performed to identify an appropriate mesh density to achieve suitably accurate results whilst maintaining computational efficiency. Models with a range of mesh sizes from five to fifteen elements across the cross-section depth yielded very similar results. Therefore, ten identical elements are employed across each flange width with an aspect ratio of close to unity.

The end conditions adopted in the model replicate those in the test, which were simply supported boundary conditions, by restraining the appropriate displacement and rotation degrees of freedom. The finite element analysis is performed in two stages. Firstly, the mechanical load is applied and then, this load is maintained whilst the elevated temperature is applied, using data from the testing program.

\subsection{Finite element model for the stainless steel cellular beam}

In this section, a finite element model is developed to simulate the behavior of a stainless steel cellular beam at elevated temperature, based on the fire test which was described earlier in this paper.

\subsubsection{Stainless steel material model}

The stainless steel grade employed in the current analysis is austenitic grade 1.4301. In the numerical model, the way in which the material is simulated both at ambient and elevated temperature is a key issue. The material model for the stress-strain response of stainless steel that is adopted in the finite model is the modified Ramberg-Osgood model [11-13] as given in Eqs. 1 and 2, and included in the SCI design manual for structural stainless steel [14].

$$
\begin{aligned}
& \varepsilon=\frac{\sigma}{\mathrm{E}_{0}}+0.002\left(\frac{\sigma}{\sigma_{0.2}}\right)^{\mathrm{n}} \text { for } \sigma \leq \sigma_{0.2} \\
& \varepsilon=\frac{\sigma-\sigma_{0.2}}{\mathrm{E}_{0.2}}+\varepsilon_{\mathrm{u}}\left(\frac{\sigma-\sigma_{0.2}}{\sigma_{\mathrm{u}}-\sigma_{0.2}}\right)^{\mathrm{m}}+\varepsilon_{0.2} \text { for } \sigma_{0.2}<\sigma \leq \sigma_{\mathrm{u}}
\end{aligned}
$$

In these expressions, $\varepsilon$ and $\sigma$ are the engineering strain and stress, respectively; $\sigma_{0.2}$ and $\varepsilon_{0.2}$ are the $0.2 \%$ proof stress and corresponding strain values, respectively; $\mathrm{E}_{0}$ is the initial Young's modulus; $\mathrm{E}_{0.2}$ is the tangent modulus at $\sigma_{0.2} ; \sigma_{\mathrm{u}}$ and $\varepsilon_{\mathrm{u}}$ are the ultimate stress and corresponding strain, respectively; and $\mathrm{n}$ and $\mathrm{m}$ are model constants related to strain hardening. In order to convert the nominal stress-strain $\left(\sigma_{\text {nom- }} \varepsilon_{\text {nom }}\right)$ values obtained from Eqs. 1 and 2 into the true stress-true logarithmic plastic strain terms required in the Abaqus model, the following expressions are employed:

$$
\sigma_{\text {true }}=\sigma_{\text {nom }}\left(1+\varepsilon_{\text {nom }}\right)
$$




$$
\varepsilon_{\text {true }}^{\mathrm{p}}=\ln \left(1+\varepsilon_{\text {nom }}\right)-\sigma_{\text {true }} / \mathrm{E}_{0}
$$

At elevated temperature, the stainless steel mechanical properties are defined according to the equations given in Eqs. 5 and 6, as given in the SCI design manual for structural stainless steel [14]:

$\varepsilon_{\theta}=\frac{\sigma_{\theta}}{\mathrm{E}_{\theta}}+0.002\left(\frac{\sigma_{\theta}}{\sigma_{0.2, \theta}}\right)^{\mathrm{n}_{\theta}}$ for $\sigma_{\theta} \leq \sigma_{0.2, \theta}$

$\varepsilon_{\theta}=\frac{\sigma_{\theta}-\sigma_{0.2, \theta}}{\mathrm{E}_{0.2, \theta}}+\varepsilon_{\mathrm{u}, \theta}\left(\frac{\sigma_{\theta}-\sigma_{0.2, \theta}}{\sigma_{\mathrm{u}, \theta}-\sigma_{0.2, \theta}}\right)^{\mathrm{m}_{\theta}}+\varepsilon_{0.2, \theta}$ for $\sigma_{0.2, \theta}<\sigma \leq \sigma_{\mathrm{u}, \theta}$

In these expressions, $\sigma_{\theta}$ and $\varepsilon_{\theta}$ are the stress and strain of stainless steel at temperature $\theta$, respectively; $\sigma_{0.2, \theta}$ and $\varepsilon_{0.2, \theta}$ are the yield strength and corresponding strain at temperature $\theta ; \mathrm{E}_{\theta}$ and $\mathrm{E}_{0.2, \theta}$ are the initial elastic modulus and tangent modulus corresponding to $\sigma_{0.2, \theta}$ at temperature $\theta$, respectively; $\varepsilon_{\mathrm{u}, \theta}$ is the ultimate strain at temperature $\theta$; and $\mathrm{n}_{\theta}$ and $\mathrm{m} \theta$ are the strain hardening constants at temperature $\theta$ for stainless steel.

\subsubsection{Thermal properties}

The constitutive behavior of the stainless steel material at ambient temperature which is represented in the model is shown in Fig. 2. The elevated temperature material properties of the steel are characterized in accordance with the nonlinear stress-strain curve at elevated temperature for stainless steel given in the Stainless Steel Design Guide [14]. This provides reduction factors to depict the degradation of the $0.2 \%$ proof strength, the ultimate strength and corresponding strain and also the elastic modulus at various levels of elevated temperature. The temperature-dependent thermal expansion of the stainless steel during heating is modelled using the method included in Eurocode 3 Part 1-2 [5], as is the specific heat and thermal conductivity. The surface emissivity for stainless steel is taken as 0.4 and the convective heat transfer coefficient of $25 \mathrm{w} / \mathrm{m}^{2} \mathrm{~K}$ are used in the analysis, in accordance with Eurocode 1 Part 1-2 [17].

\subsubsection{Boundary and loading conditions}

The geometrical and loading conditions of the beam are modelled to simulate the exact condition of the test specimen discussed in Section 2 of this paper. As such, the stainless steel cellular beam is symmetrical about the mid-span. The end sections have simply supported boundary conditions with a pin condition at one end and a roller at the other. Therefore the vertical and lateral displacements of all nodes on the bottom flange at the support sections are restrained against movement and therefore assigned values equal to zero. The roller end is free to move horizontally in the longitudinal axis. The simulation of the tested beam is carried out in two stages, as occurred in the test. In the first stage, the mechanical load is applied and then the beam is subjected to the thermal load. The steel temperature history obtained during the test is applied at various locations of the beam i.e. top flange, web and bottom flange as the thermal load. 


\subsubsection{Geometric imperfections and residual stresses}

All structural members contain geometric imperfections which are introduced during production, fabrication and handling. Initial imperfections in the form of the lowest local and global buckling mode, obtained from a linear elastic eigenvalue buckling analysis, are included in the numerical model. These have amplitudes of $0.48 \mathrm{~mm}$ and $4.3 \mathrm{~mm}$ for local and global buckling modes, respectively, as measured in the test specimens. Residual stresses, likewise introduced to during manufacturing (e.g. cold-forming) or welding, are not explicitly incorporated into the models due to their low measured amplitudes and minimal influence on the member behavior in similar studies [15].

\subsubsection{Comparison with the test results}

The experimental and numerical results for the development of mid-span deflection with increasing time is presented in Fig. 9(a). The equivalent values for the horizontal beam end displacements versus time are given in Fig. 9(b). Clearly, an excellent agreement has been obtained between the simulation and the test results. The model depicts all of the major behavioral phenomena, particularly the large increase in deflections that occurs in the later stages of the analysis. There are some minor discrepancies in the early stages of the test in terms of the end displacement results in Fig. 9(b), and these are most likely due to some initial movement in the test specimen upon the application of loading.

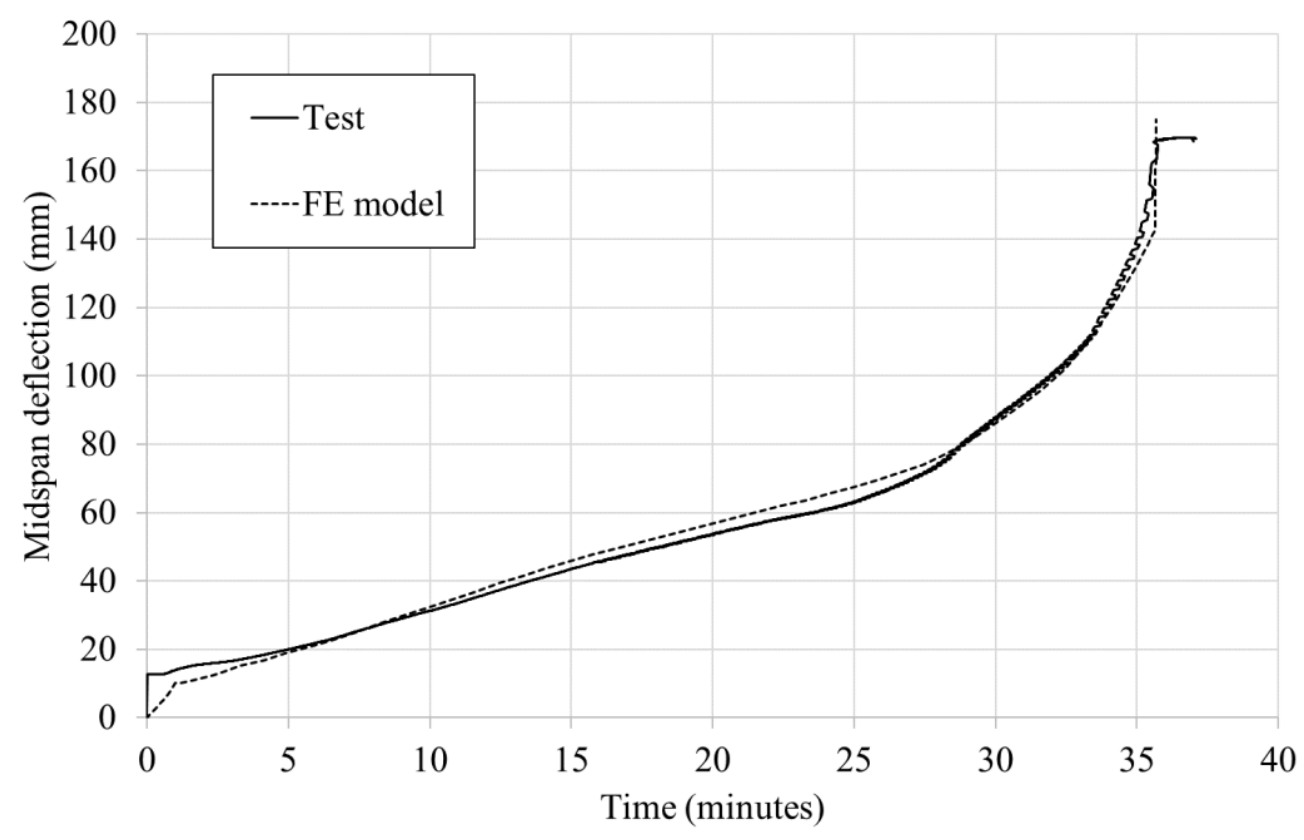

(a) 


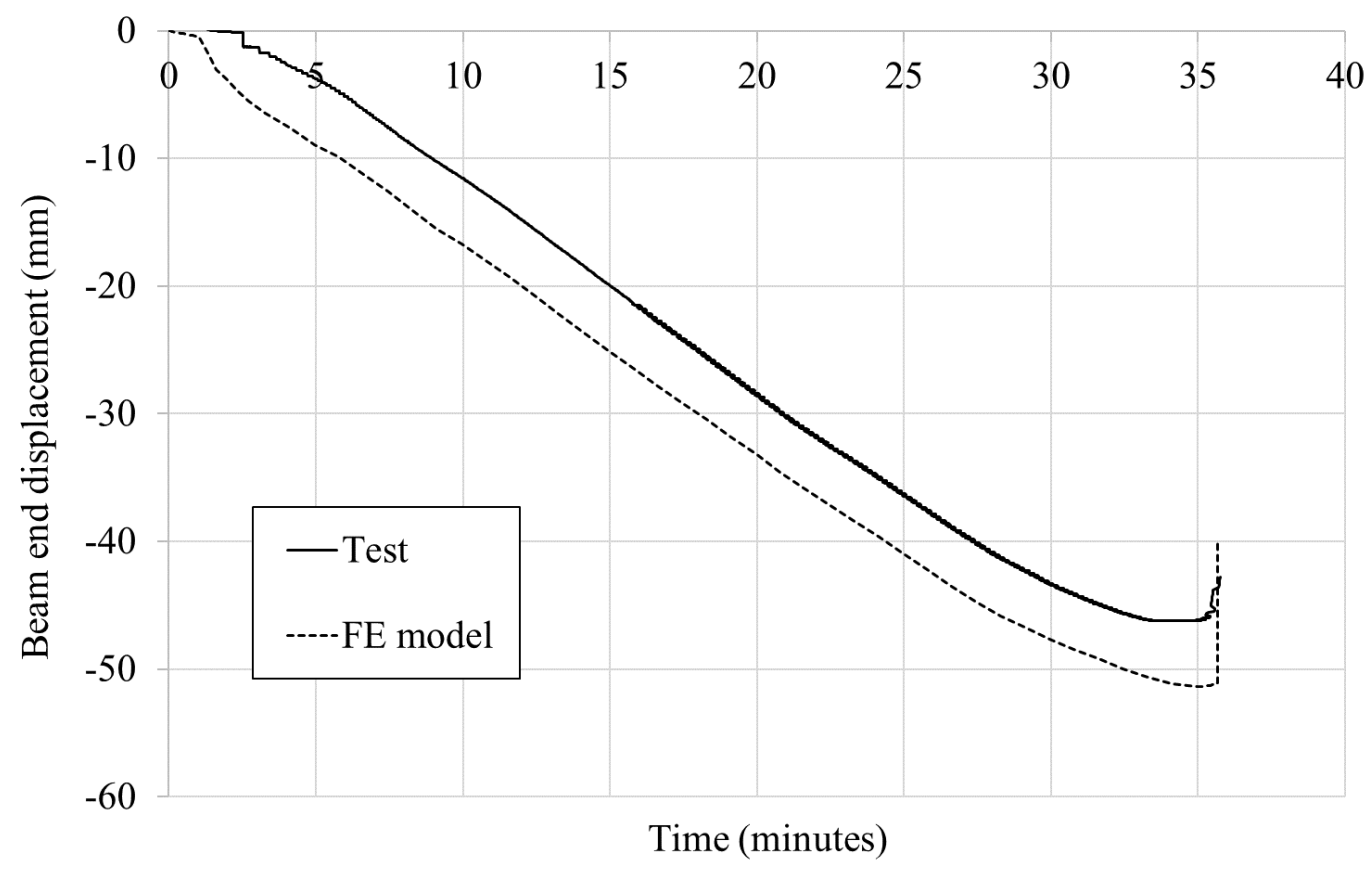

(b)

Fig. 9. Comparison between the experimental results and FE simulations for (a) deflection versus time and (b) horizontal beam end displacements versus time

In order to provide a more robust validation of the numerical model, and due to a lack of any further testing on stainless steel cellular beams, the model is employed to examine the carbon steel cellular beams examined by Yin et al. [18]. The structure is modelled based on the geometry of a $457 \times 152 \times 60$ UB (universal beam) in grade S275 structural steel and a span of $8 \mathrm{~m}$. It has multiple rectangular web openings as shown in Fig. 10(a). A uniformly distributed load of $35 \mathrm{kN} / \mathrm{m}$, giving a load ratio of 0.7 based on the ambient temperature capacity of the beams, is applied to the upper surface of the member. The analysis is conducted in two steps. In the first step the static load is applied and in the second step, a uniform temperature distribution in the cross-section is applied until failure occurs.

Fig. 10(b) shows the temperature versus midspan deflection behavior for this steel cellular beam, from both the numerical model and those published elsewhere [18]. It is clear that a very good agreement is obtained. The shapes of the responses are identical and almost perfectly match. There are two stages in the fire behavior of simply supported steel cellular beams. In the first stage, up to about $250^{\circ} \mathrm{C}$, there is very little deflection in the beam due to the absence of thermal gradient in the section as well as the absence of any horizontal resistance to the development of thermal expansion. Later, as the temperature increases, there is a significant decrease in the strength properties of the material, causing the top tee-section of the cellular beam to buckle under high compressive forces and deflections to increase rapidly until a runaway failure occurs. 
In conclusion to this section, it is considered that the numerical model is capable of capturing the key behavioral aspects of cellular beams at elevated temperature.

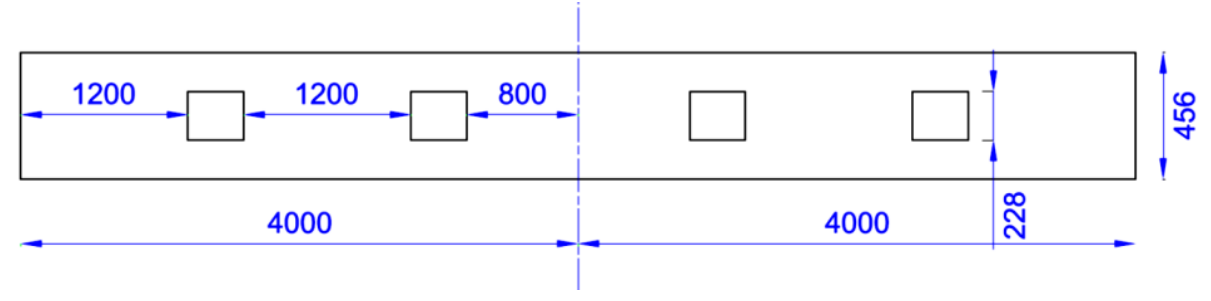

(a)

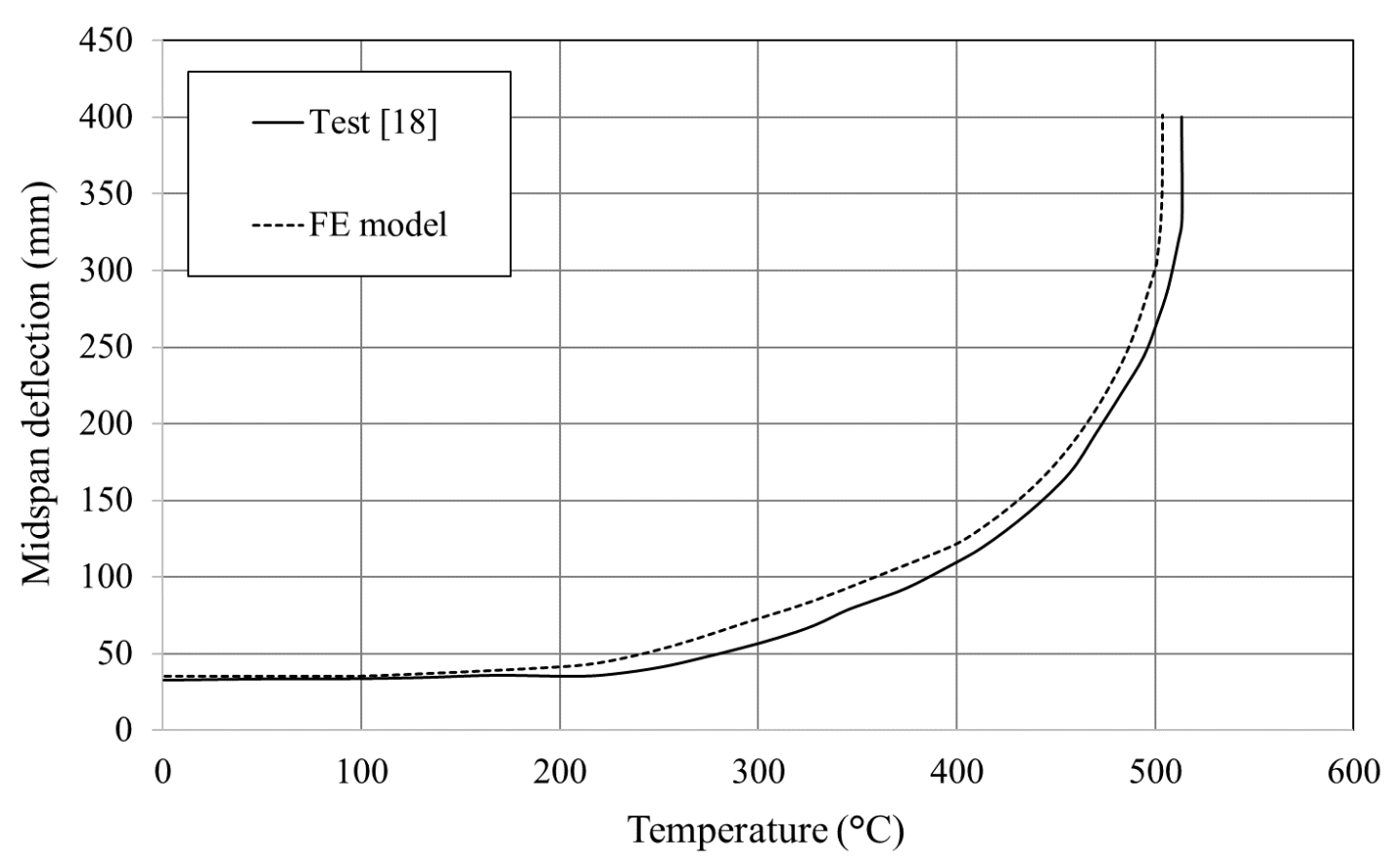

(b)

Fig. 10. Validation of the cellular beam experiment conducted elsewhere [18] illustrating (a) the beam arrangement (all units in $\mathrm{mm}$ ) and (b) the mid-span deflection versus temperature

\section{Parametric study}

Following the validation of the numerical model presented in the previous section, the FE model is employed to conduct an extensive parametric study to analyze the response of unrestrained stainless steel cellular beams in fire. The effect of load ratio, type of loading and steel grade on the fire behavior of these beams is studied. The various parameters considered in the study include three different load ratios (namely 0.3, 0.4 and 0.5 ), three different grades of metallic material (austenitic and ferritic stainless steel as well as carbon steel) and three different loading 
types i.e., three point loading (3 PL), four point loading (4 PL) and uniformly distributed loading (UDL). All the beams were exposed to a standard fire and a heat transfer analysis was performed to estimate the temperatures at various locations in the beam. Fig. 11 shows the temperatures after the heat transfer analysis at various locations in the cross-section of austenitic stainless steel beams. It is noteworthy that the temperatures in the top and bottom flanges are identical as they were both subject to the same standard fire and hence these lines overlap in the figure. Similarly, the temperature history has been obtained for ferritic stainless steel and carbon steel beams. All cases included in the parametric study are summarized in Table 1.

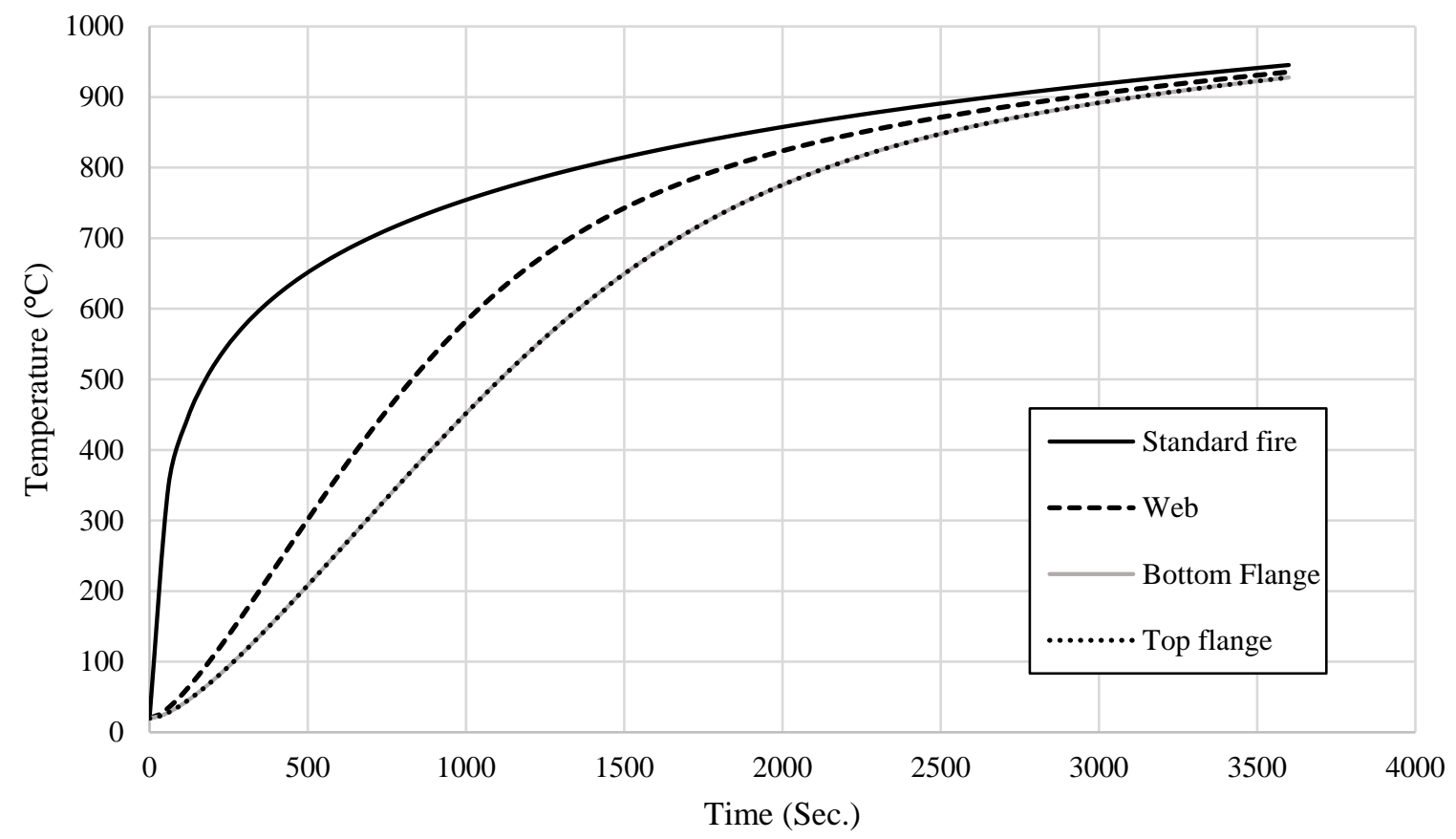

Fig. 11 Temperature history at various location for austenitic steel beam from heat transfer analysis 
Table 1 Summary of the parametric study

\begin{tabular}{|c|c|c|c|}
\hline No. & Material Grade & Load Ratio & Loading Type \\
\hline 1 & Grade 1.4301 (austenitic stainless steel) & 0.3 & $3 \mathrm{PL}$ \\
\hline 2 & Grade 1.4301 (austenitic stainless steel) & 0.3 & $4 \mathrm{PL}$ \\
\hline 3 & Grade 1.4301 (austenitic stainless steel) & 0.3 & UDL \\
\hline 4 & Grade 1.4301 (austenitic stainless steel) & 0.4 & $3 \mathrm{PL}$ \\
\hline 5 & Grade 1.4301 (austenitic stainless steel) & 0.4 & $4 \mathrm{PL}$ \\
\hline 6 & Grade 1.4301 (austenitic stainless steel) & 0.4 & UDL \\
\hline 7 & Grade 1.4301 (austenitic stainless steel) & 0.5 & $3 \mathrm{PL}$ \\
\hline 8 & Grade 1.4301 (austenitic stainless steel) & 0.5 & $4 \mathrm{PL}$ \\
\hline 9 & Grade 1.4301 (austenitic stainless steel) & 0.5 & UDL \\
\hline 10 & Grade 1.4003 (ferritic stainless steel) & 0.3 & $3 \mathrm{PL}$ \\
\hline 11 & Grade 1.4003 (ferritic stainless steel) & 0.3 & $4 \mathrm{PL}$ \\
\hline 12 & Grade 1.4003 (ferritic stainless steel) & 0.3 & UDL \\
\hline 13 & Grade 1.4003 (ferritic stainless steel) & 0.4 & $3 \mathrm{PL}$ \\
\hline 14 & Grade 1.4003 (ferritic stainless steel) & 0.4 & $4 \mathrm{PL}$ \\
\hline 15 & Grade 1.4003 (ferritic stainless steel) & 0.4 & UDL \\
\hline 16 & Grade 1.4003 (ferritic stainless steel) & 0.5 & $3 \mathrm{PL}$ \\
\hline 17 & Grade 1.4003 (ferritic stainless steel) & 0.5 & $4 \mathrm{PL}$ \\
\hline 18 & Grade 1.4003 (ferritic stainless steel) & 0.5 & UDL \\
\hline 19 & Carbon steel $\left(\mathrm{f}_{\mathrm{y}}=520 \mathrm{~N} / \mathrm{mm}^{2}\right)$ & 0.3 & $3 \mathrm{PL}$ \\
\hline 20 & Carbon steel $\left(\mathrm{f}_{\mathrm{y}}=520 \mathrm{~N} / \mathrm{mm}^{2}\right)$ & 0.3 & $4 \mathrm{PL}$ \\
\hline 21 & Carbon steel $\left(\mathrm{f}_{\mathrm{y}}=520 \mathrm{~N} / \mathrm{mm}^{2}\right)$ & 0.3 & UDL \\
\hline 22 & Carbon steel $\left(\mathrm{f}_{\mathrm{y}}=520 \mathrm{~N} / \mathrm{mm}^{2}\right)$ & 0.4 & $3 \mathrm{PL}$ \\
\hline 23 & Carbon steel $\left(\mathrm{f}_{\mathrm{y}}=520 \mathrm{~N} / \mathrm{mm}^{2}\right)$ & 0.4 & $4 \mathrm{PL}$ \\
\hline 24 & Carbon steel $\left(\mathrm{f}_{\mathrm{y}}=520 \mathrm{~N} / \mathrm{mm}^{2}\right)$ & 0.4 & UDL \\
\hline 25 & Carbon steel $\left(\mathrm{f}_{\mathrm{y}}=520 \mathrm{~N} / \mathrm{mm}^{2}\right)$ & 0.5 & $3 \mathrm{PL}$ \\
\hline 26 & Carbon steel $\left(\mathrm{f}_{\mathrm{y}}=520 \mathrm{~N} / \mathrm{mm}^{2}\right)$ & 0.5 & $4 \mathrm{PL}$ \\
\hline 27 & Carbon steel $\left(\mathrm{f}_{\mathrm{y}}=520 \mathrm{~N} / \mathrm{mm}^{2}\right)$ & 0.5 & UDL \\
\hline
\end{tabular}

\subsection{Load ratio}

Fig. 12 presents the bottom flange temperature versus mid-span vertical deflection behavior for beams with three different load ratios. The results are presented for cellular beams made from austenitic stainless beams for illustrative purposes and similar results have also been obtained for cellular beams made from ferritic stainless steel and carbon steel. All of the beams are subjected to 3 point loading. It is shown that the overall behavior of cellular beams in fire is not particularly affected by the load ratio and as expected, the fire resistance generally decreases with an increase in load ratio irrespective of the steel grade and loading type. It is observed that the fire resistance of austenitic stainless steel cellular beams is more influenced by a change in load ratio (LR) compared with carbon steel and ferritic stainless steel beams. For the 3 point loading arrangement and an increase of LR from 0.3 to 0.5 , the fire resistance temperature for austenitic steel beams decreases by $130^{\circ} \mathrm{C}$. 


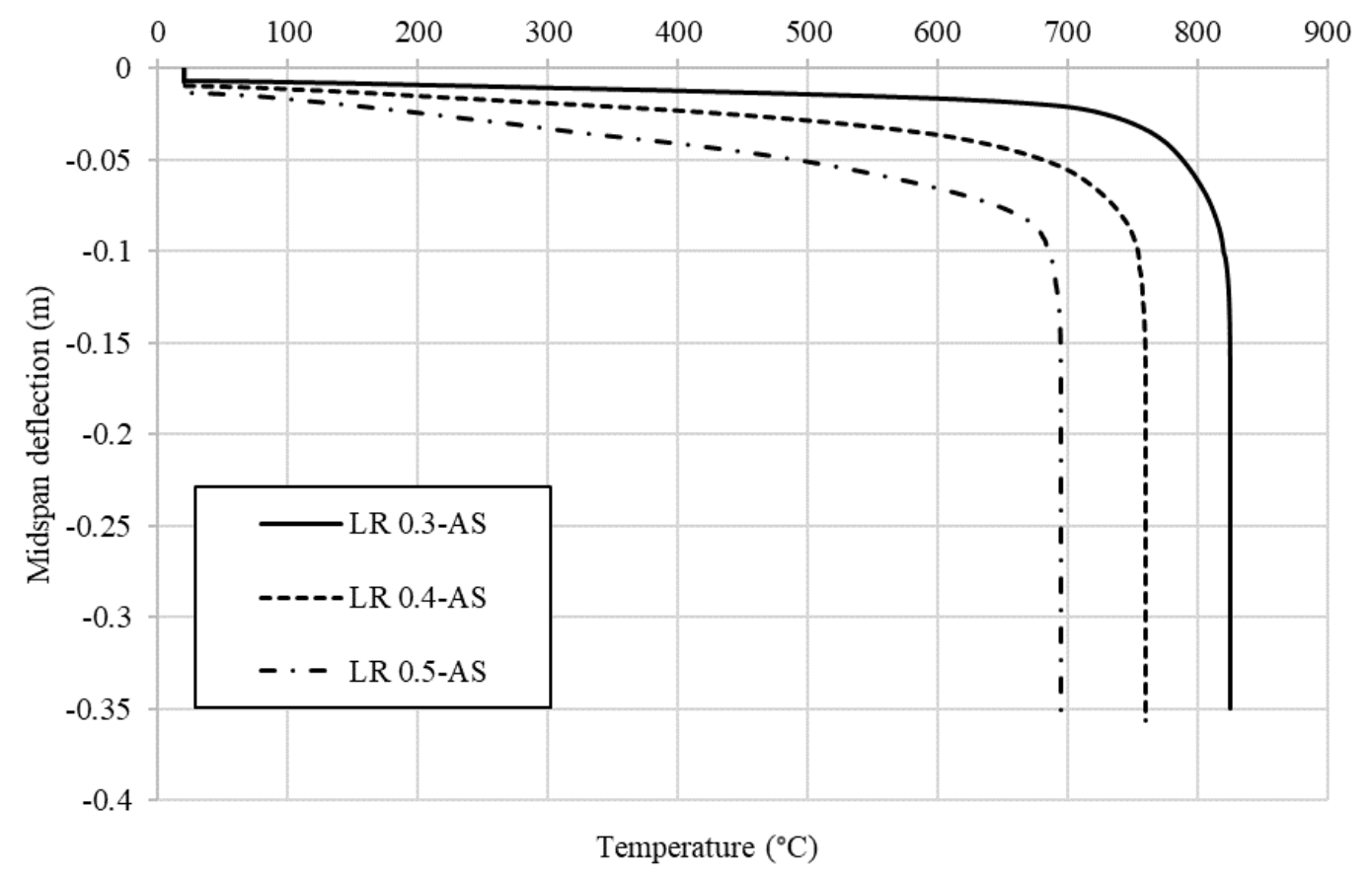

Fig. 12 Mid-span deflection versus bottom flange temperature for cellular beams subjected to different levels of load ratio and made from austenitic stainless steel

On the other hand, for carbon steel and ferritic stainless steel cellular beams, the equivalent reductions are $80^{\circ} \mathrm{C}$ and $70{ }^{\circ} \mathrm{C}$, respectively. This is attributed to the fact that austenitic stainless steel is a very ductile material compared to carbon steel and even ferritic stainless steel, resulting in the mid-span deflections for austenitic stainless steel cellular beams being more sensitive to load ratio.

The analysis shows that although the failure temperature may not be greatly influenced by load ratio, the failure modes are likely to be more sensitive to this property. At low levels of load ratio, the stainless steel cellular beams fail due to a combination of lateral torsional buckling, web-post buckling and buckling of top tee as shown in Fig. 13. The Vierendeel mechanism is not observed at load ratio of 0.3 due to the low Vierendeel moments. On other hand, for higher levels of load ratio, the primary failure mode is a combination of Vierendeel bending and web-post buckling due to the development of high Vierendeel moments. 


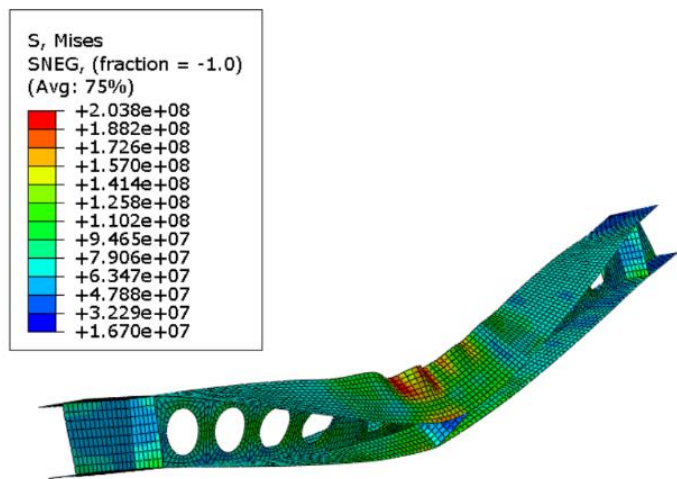

(a)

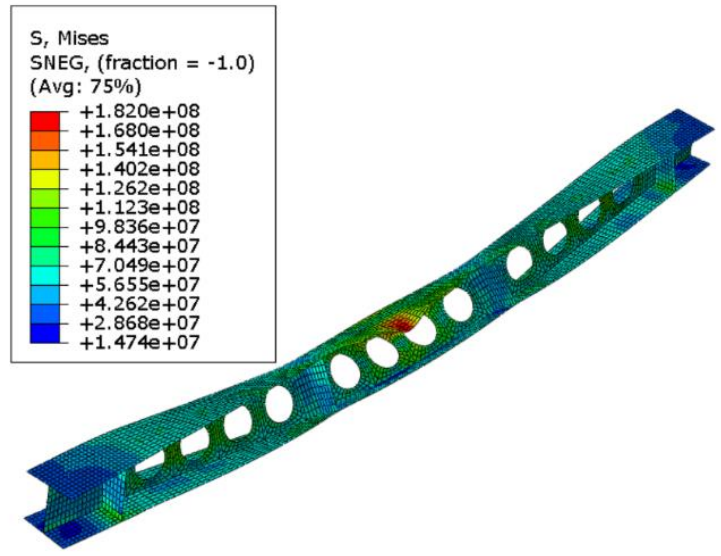

(c)

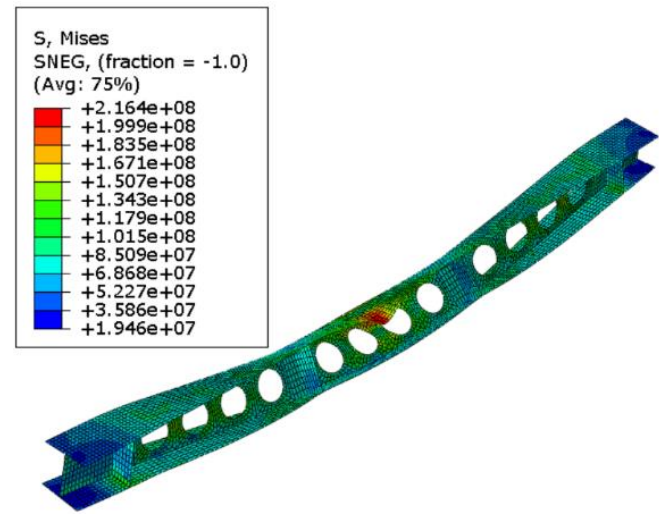

(e)

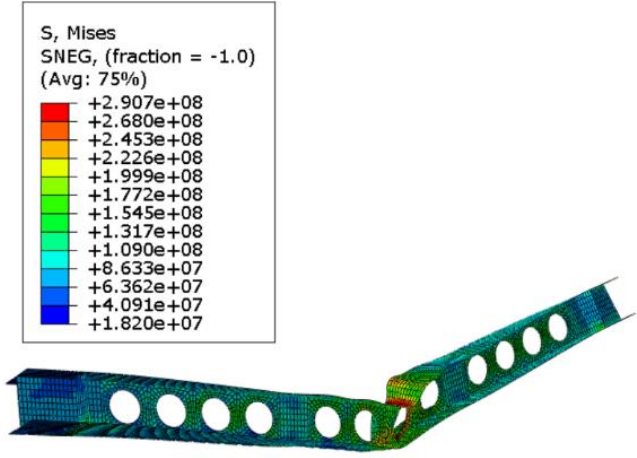

(b)

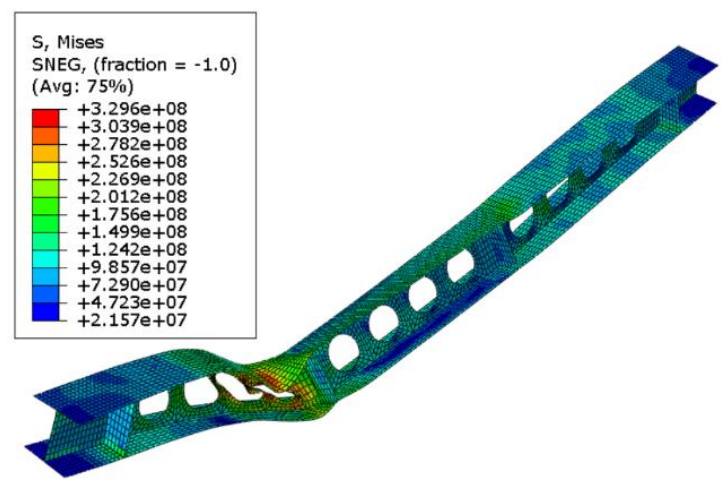

(d)

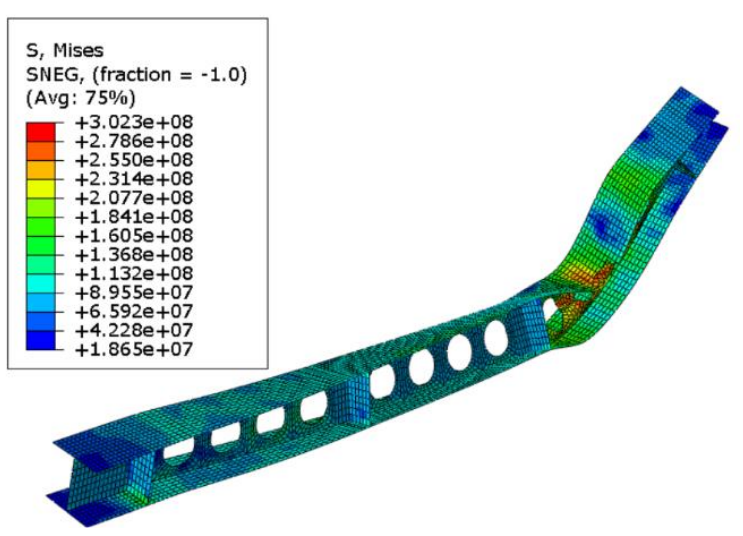

(f)

Fig. 13 Images from the FE model illustrating the failure modes for austenitic stainless steel cellular beams with (a) LR of 0.3 and 3 point loading (b) LR of 0.5 and 3 point loading, (c) LR of 0.3 and 4 point loading, (d) LR of 0.5 and 4 point loading, (e) LR of 0.3 and UDL, and (f) LR of 0.5 and UDL 


\subsection{Loading type}

For all of the beams examined in the current program, the temperature versus mid-span deflection behavior remains relatively unaffected by the three types of loading arrangement considered. The results are presented in Fig. 14 for cellular beams made from austenitic stainless beams under different loading arrangements at a load ratio of 0.3 . This case is selected for illustrative purposes, and similar results have also been obtained for the other grades of steel as well as different load ratios. For all three loading arrangements, the fire resistance temperature for beams made from austenitic stainless steel, ferritic stainless steel and carbon steel is around $840{ }^{\circ} \mathrm{C}, 770{ }^{\circ} \mathrm{C}$ and 675 , respectively. On the other hand, the mode of failure is greatly influenced by the type of loading arrangement. For three-point loading, at a load ratio of 0.3 , the failure mode is primarily buckling of the top tee followed by lateral torsional buckling. Whereas for a higher load ratio, the dominating failure mode is lateral torsional buckling along with webpost buckling.

For 3-point loading arrangements, failure due to Vierendeel bending is observed at the midsection and this is attributed to the difference in bending moments due to the variation in shear forces from one side of the opening to the other side, thus resulting in relatively high Vierendeel moments. However, for the 4-point loading arrangement, at relatively low levels of load ratio, the failure starts with lateral torsional buckling which is then followed by buckling of the webpost in an S shape. At higher load ratios, the primary failure mode is Vierendeel bending with web-post buckling due to the transfer of high levels of shear force across the opening near the loading points. For a UDL arrangement, the failure modes are very similar to those observed for the 4-point loading arrangement. At low load ratios, the failure is initiated by buckling of the top flange followed by lateral torsional buckling. At higher load ratio, failure occurs due to the formation of a Vierendeel mechanism. The location of the Vierendeel mechanism is governed by where the change of shear force occurs (i.e. due to the loading arrangement). It occurs when the difference in shear force from one side of an opening to the other is relatively large. 


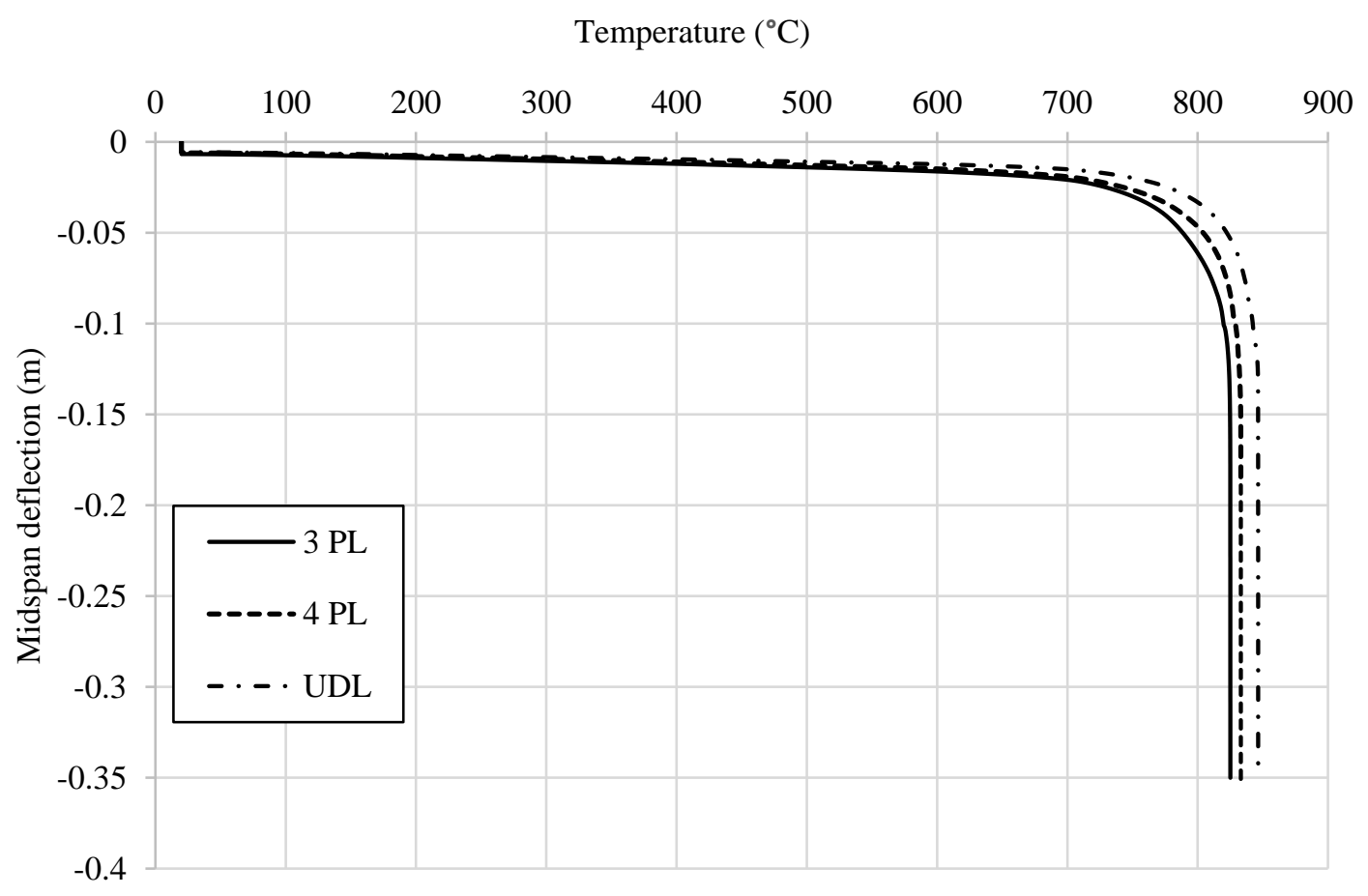

Fig. 14 Mid-span deflection versus bottom flange temperature for austenitic stainless steel cellular beams subjected to different loading types

\subsection{Material type}

The fire resistance temperature varies greatly for beams made using different types of steel. In this section, cellular beams made from three different material types including austenitic stainless steel (AS), ferritic stainless steel (FS) and carbon steel (CS) are modelled to assess the influence that this has on the behavior. The constitutive relationship for each material is presented in Fig. 15. 


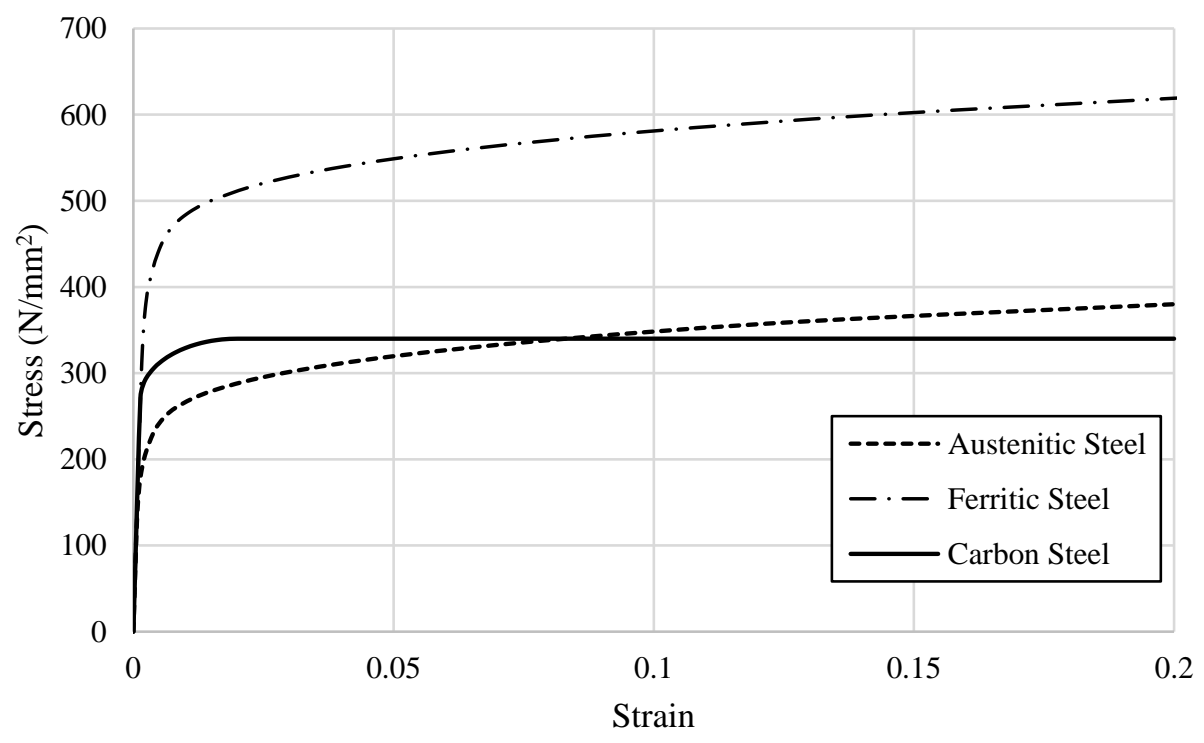

Fig. 15 Stress-strain response for the different materials included in the study

Fig. 16 presents a comparison of the midspan deflection versus bottom flange temperature behavior for beams made from austenitic stainless steel (AS), ferritic stainless steel (FS) and carbon steel (CS) for load ratios (LR) of (a) 0.3 and (b) 0.5. It is shown that for both load ratios, the fire resistance of austenitic stainless steel beams is the greatest of the three materials examined herein, followed by the beams made from ferritic stainless steel and then carbon steel. When the load ratio equals 0.3 , the difference between the fire resistance of austenitic and ferric stainless steel beams is similar to the difference between ferritic stainless steel and carbon steel beams. However, as the load ratio increases, the difference in the fire resistance temperature between the austenitic and ferritic stainless steel beams becomes less significant, as shown in Fig. 16, whilst the carbon steel still performs significantly worse than both. This is due to the fact that the mid-span deflection of the austenitic stainless steel cellular beams are sensitive to load ratio owing to their high ductility as stated before. The failure modes were previously shown to be greatly influenced by the loading arrangement and load ratio but is less sensitive to the type of steel material. 


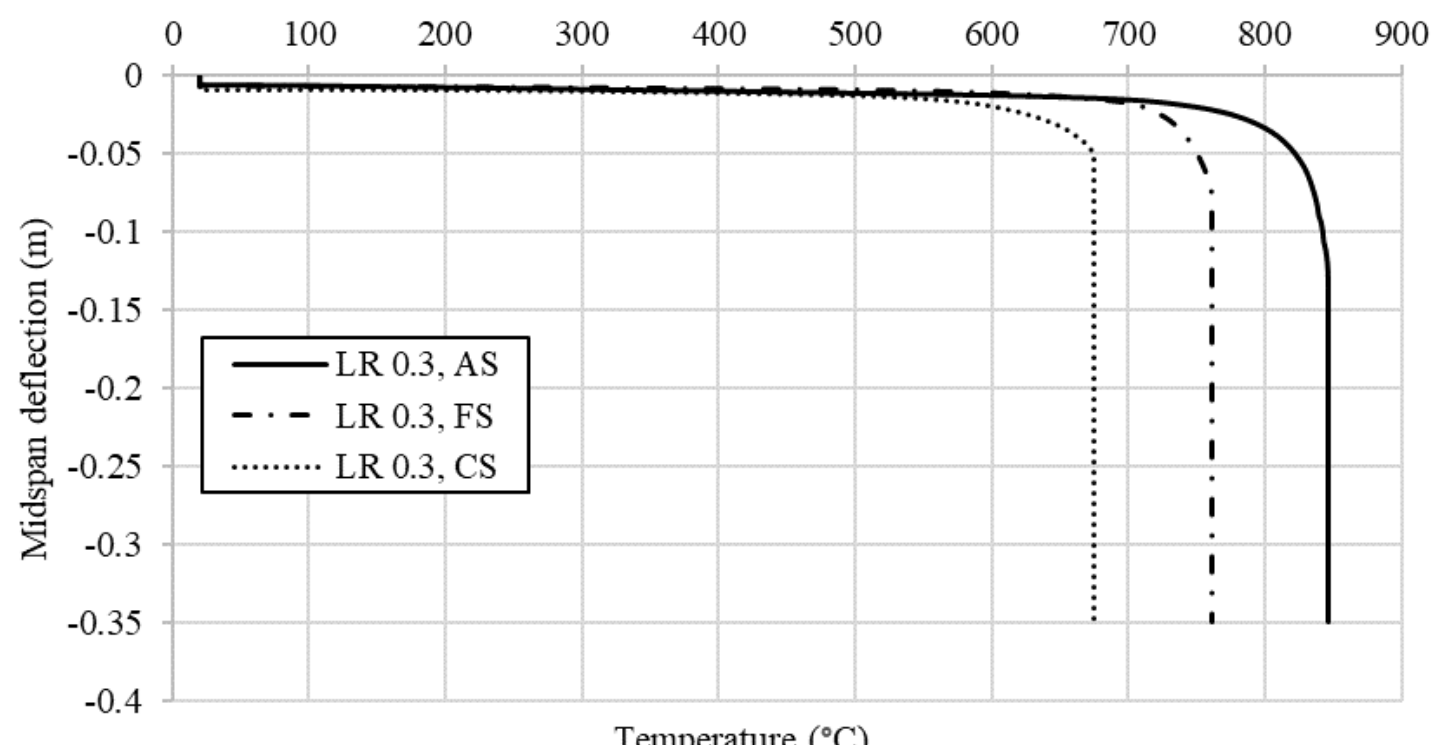

Temperature $\left({ }^{\circ} \mathrm{C}\right)$

(a)

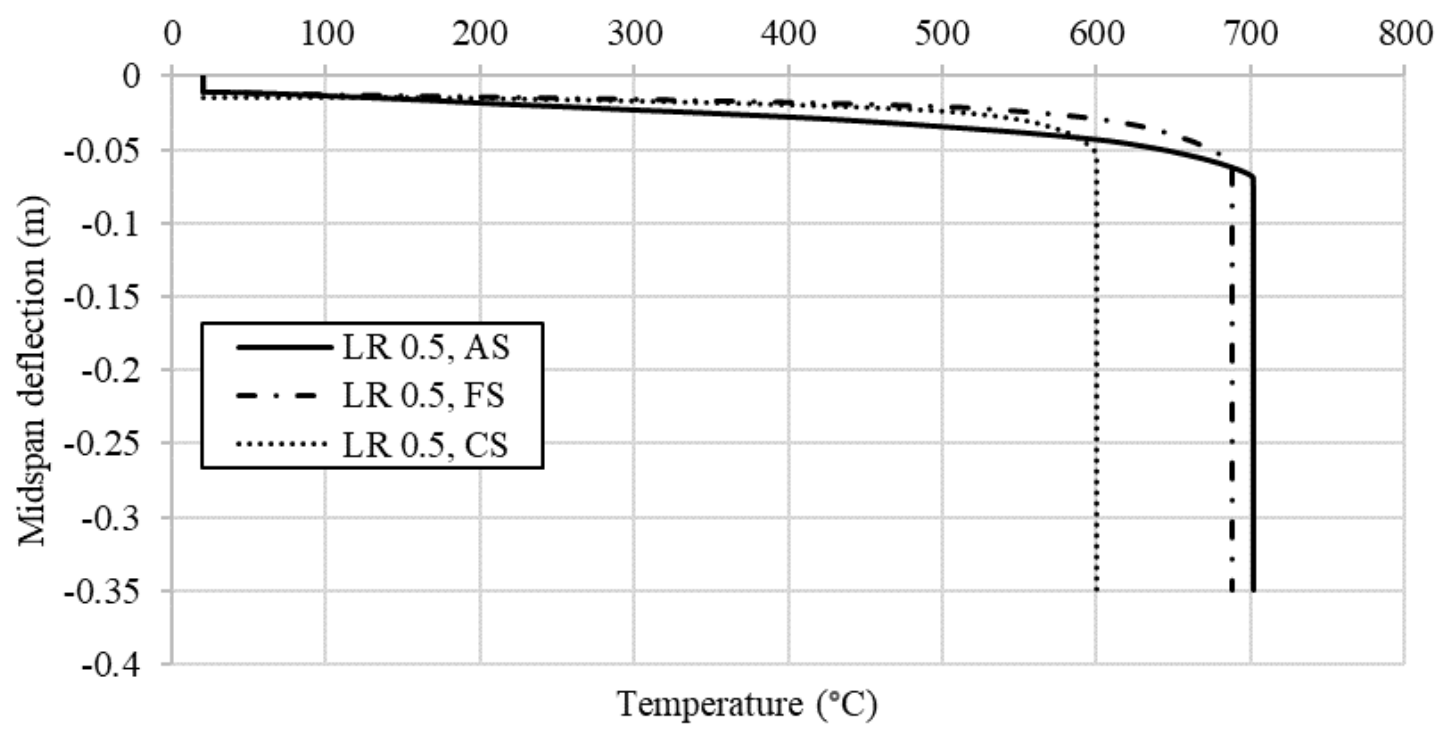

(b)

Fig. 16 Comparison for cellular beams made from different materials for (a) $L R=0.3$ and (b)

$$
\mathrm{LR}=0.5
$$

\section{Conclusions}

This paper has presented a discussion and analysis of a study into the fire behavior of stainless steel cellular beams. A full-scale fire resistance test was conducted on a stainless steel cellular beam subject to pure bending. The beam failed by web-post buckling 28 minutes after the ignition of the furnace, despite having no fire protection. At failure, the furnace and the average web temperatures at mid-span were $840{ }^{\circ} \mathrm{C}$ and $759{ }^{\circ} \mathrm{C}$, respectively. In accordance with the classification standard EN 13501-2 [9] the loss of load bearing capacity occurred 34 minutes after the ignition. 
The paper also presented an overview of the development of a finite element model which is capable of representing the behavior of stainless steel cellular beams under elevated temperature loading conditions. The model is developed in the Abaqus software and is validated using the experiential data from the fire test. The model is shown to provide an excellent depiction of the behavior. It is then employed to present an analysis of some of the critical performance parameters. It is shown that the loading arrangement is not hugely influential to the length of time that the beam the unprotected stainless steel cellular beam survives but the fire resistance of the beams generally decreases with an increase in load ratio for all steel grades. Both the loading arrangement and the load ratio are shown to be much more influential in terms of the failure mode. On the other hand, one of the most significant findings from the current study is that stainless steel beams perform significantly better in terms of survival time and deflections, compared with carbon steel cellular beams. The austenitic grades are particularly good, but even the ferritic stainless steel beams studied herein outperformed the carbon steel cellular beams.

\section{Acknowledgements}

The research leading to this paper was part-funded by the Tampere University and the Brunel University London. The test specimen provided by Stalatube Oy Finland is gratefully acknowledged.

\section{References}

[1] New Steel Construction. An introduction to cellular beams. New Steel Construction. http://www.newsteelconstruction.com/wp/an-introduction-to-cellular-beams/

[2] Nadjai, A., Petrou, K., Han, S. and Ali, F. Performance of unprotected and protected cellular beams in fire conditions. Construction and Building Materials, 2016. 105: 579-588.

[3]. Mesquita, L., Gonçalves, J., Gonçalves, G., Piloto, O. and Abdelhak, K. Intumescent fire protection of cellular beams. Congresso de Construcao Metalica e Mista, 2015. Portugal.

[4]. Gardner, L. and Baddoo, N.R. Fire testing and design of stainless steel structures. Journal of Constructional Steel Research, 2006. 62(6): 532-543.

[5] EN 1993-1-2:2005. Eurocode 3: Design of steel structures. Part 1-2: General rules Structural fire design. Brussels, Belgium: European Committee for Standardization, 2005.

[6] Gardner, L. and Ng., K. Temperature development in structural stainless steel sections exposed to fire. Fire Safety Journal, 2006. 41(3):185-203.

[7] EN 1365-3:1999. Fire resistance tests for loadbearing elements. Part 3: Beams. Brussels, Belgium : European Committee for Standardization, 1999.

[8] EN 1363-1:2012. Fire resistance test. Part 1: General requirements. Brussels, Belgium : European Committee of Standardization, 2012. 
[9] EN 13501-2:2016. Fire classification of construction products and building elements. Part 2: Classification using data from fire resistance tests, excluding ventilation services. Brussels, Belgium : European Committee for Standardization, 2016.

[10] Abaqus. ABAQUS Documentation, Dassault Systèmes, U.S.A. 2010.

[11] Ramberg, W. and Osgood, W.R. Description of stress-strain curves by three parameters. NACA Technical Note 902, 1943.

[12] Mirambell, E. and Real, E. On the calculation of deflections in structural stainless steel beams: an experimental and numerical investigation. Journal of Constructional Steel Research, 2000. 54(1):109-133.

[13] Rasmussen, K.J.R. Full-range stress-strain curves for stainless steel alloys. Journal of Constructional Steel Research, 2003. 59(1):47-61.

[14] Euro Inox/SCI. Design manual for structural stainless steel, 4th edition. Euro Inox and the Steel Construction Institute, 2018.

[15] Vila Real, P.M.M., Cazeli, R., Simoes da Silva, L., Santiago, A. and Piloto, P. The effect of residual stresses in the lateral-torsional buckling of steel I-beams at elevated temperature. Journal of Constructional Steel Research, 2004. 60:783-93.

[16] Fan, S., He, B., Xia, X., Gui, H., Liu, M. Fire resistance of stainless steel beams with rectangular hollow section: Experimental investigation. Fire Safety Journal, 2016. 81:17-31.

[17] EN 1991-1-2:2002. Eurocode 1: Actions on structures. Part 1-2: General actions - Actions on structures exposed to fire. Brussels, Belgium: European Committee for Standardization, 2002.

[18] Yin, Y.Z., Wang, Y.C. Analysis of behaviour of steel beams with web openings at elevated temperatures. Steel and Composite Structures, 2006. 6:15-31. 
Table 2 Summary of the parametric study

\begin{tabular}{|c|c|c|c|}
\hline No. & Material Grade & Load Ratio & Loading Type \\
\hline 1 & Grade 1.4301 (austenitic stainless steel) & 0.3 & $3 \mathrm{PL}$ \\
\hline 2 & Grade 1.4301 (austenitic stainless steel) & 0.3 & $4 \mathrm{PL}$ \\
\hline 3 & Grade 1.4301 (austenitic stainless steel) & 0.3 & UDL \\
\hline 4 & Grade 1.4301 (austenitic stainless steel) & 0.4 & $3 \mathrm{PL}$ \\
\hline 5 & Grade 1.4301 (austenitic stainless steel) & 0.4 & $4 \mathrm{PL}$ \\
\hline 6 & Grade 1.4301 (austenitic stainless steel) & 0.4 & UDL \\
\hline 7 & Grade 1.4301 (austenitic stainless steel) & 0.5 & $3 \mathrm{PL}$ \\
\hline 8 & Grade 1.4301 (austenitic stainless steel) & 0.5 & $4 \mathrm{PL}$ \\
\hline 9 & Grade 1.4301 (austenitic stainless steel) & 0.5 & UDL \\
\hline 10 & Grade 1.4003 (ferritic stainless steel) & 0.3 & $3 \mathrm{PL}$ \\
\hline 11 & Grade 1.4003 (ferritic stainless steel) & 0.3 & $4 \mathrm{PL}$ \\
\hline 12 & Grade 1.4003 (ferritic stainless steel) & 0.3 & UDL \\
\hline 13 & Grade 1.4003 (ferritic stainless steel) & 0.4 & $3 \mathrm{PL}$ \\
\hline 14 & Grade 1.4003 (ferritic stainless steel) & 0.4 & $4 \mathrm{PL}$ \\
\hline 15 & Grade 1.4003 (ferritic stainless steel) & 0.4 & UDL \\
\hline 16 & Grade 1.4003 (ferritic stainless steel) & 0.5 & $3 \mathrm{PL}$ \\
\hline 17 & Grade 1.4003 (ferritic stainless steel) & 0.5 & $4 \mathrm{PL}$ \\
\hline 18 & Grade 1.4003 (ferritic stainless steel) & 0.5 & UDL \\
\hline 19 & Carbon steel $\left(\mathrm{f}_{\mathrm{y}}=520 \mathrm{~N} / \mathrm{mm}^{2}\right)$ & 0.3 & $3 \mathrm{PL}$ \\
\hline 20 & Carbon steel $\left(\mathrm{f}_{\mathrm{y}}=520 \mathrm{~N} / \mathrm{mm}^{2}\right)$ & 0.3 & $4 \mathrm{PL}$ \\
\hline 21 & Carbon steel $\left(\mathrm{f}_{\mathrm{y}}=520 \mathrm{~N} / \mathrm{mm}^{2}\right)$ & 0.3 & UDL \\
\hline 22 & Carbon steel $\left(\mathrm{f}_{\mathrm{y}}=520 \mathrm{~N} / \mathrm{mm}^{2}\right)$ & 0.4 & $3 \mathrm{PL}$ \\
\hline 23 & Carbon steel $\left(\mathrm{f}_{\mathrm{y}}=520 \mathrm{~N} / \mathrm{mm}^{2}\right)$ & 0.4 & $4 \mathrm{PL}$ \\
\hline 24 & Carbon steel $\left(\mathrm{f}_{\mathrm{y}}=520 \mathrm{~N} / \mathrm{mm}^{2}\right)$ & 0.4 & UDL \\
\hline 25 & Carbon steel $\left(\mathrm{f}_{\mathrm{y}}=520 \mathrm{~N} / \mathrm{mm}^{2}\right)$ & 0.5 & $3 \mathrm{PL}$ \\
\hline 26 & Carbon steel $\left(\mathrm{f}_{\mathrm{y}}=520 \mathrm{~N} / \mathrm{mm}^{2}\right)$ & 0.5 & $4 \mathrm{PL}$ \\
\hline 27 & Carbon steel $\left(\mathrm{f}_{\mathrm{y}}=520 \mathrm{~N} / \mathrm{mm}^{2}\right)$ & 0.5 & UDL \\
\hline
\end{tabular}




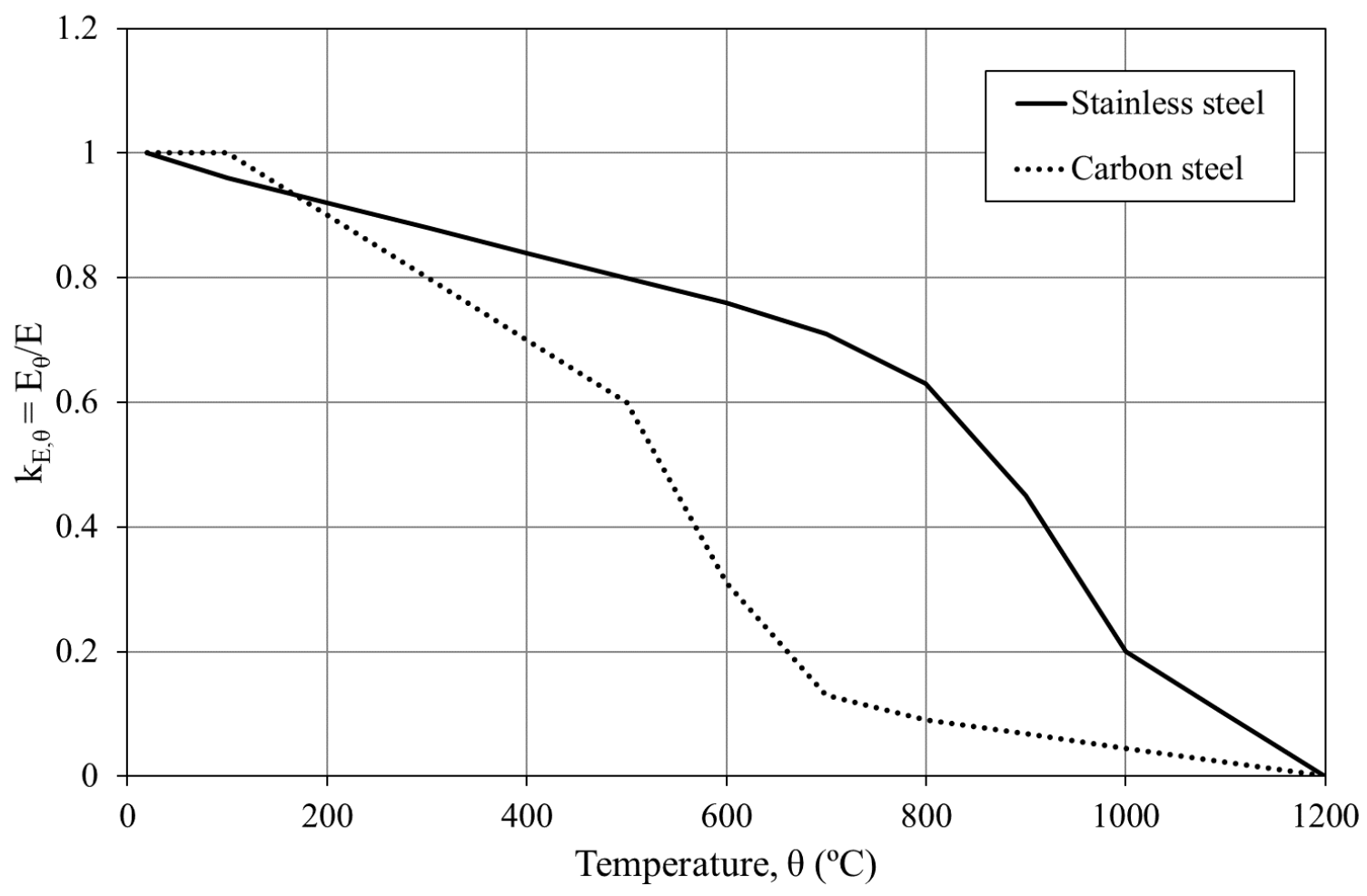

Fig. 1. Stiffness retention for stainless steel and carbon steel at elevated temperatures 


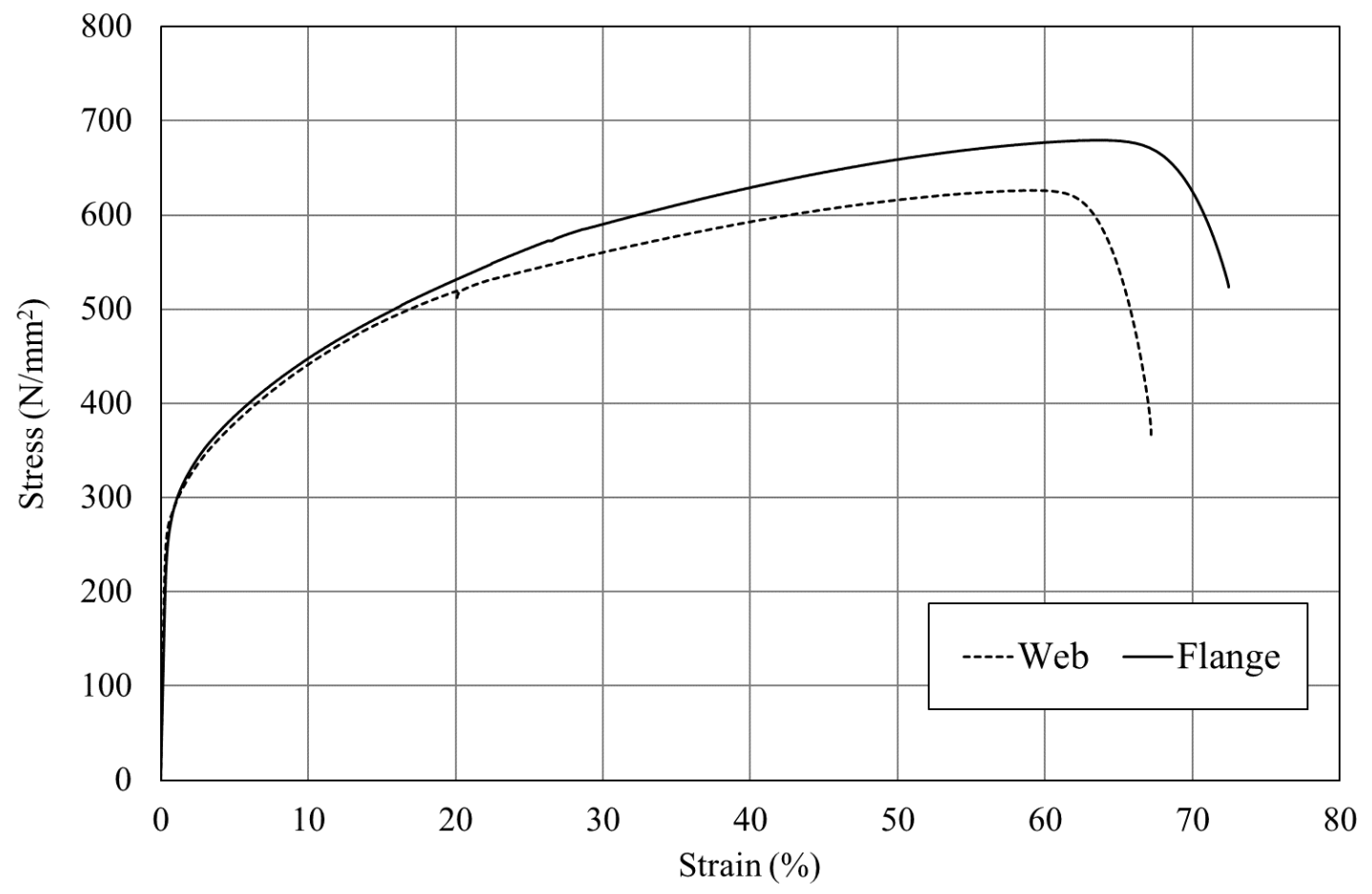

Fig. 2. Stress-strain response of the austenitic stainless steel material used in the test beam 


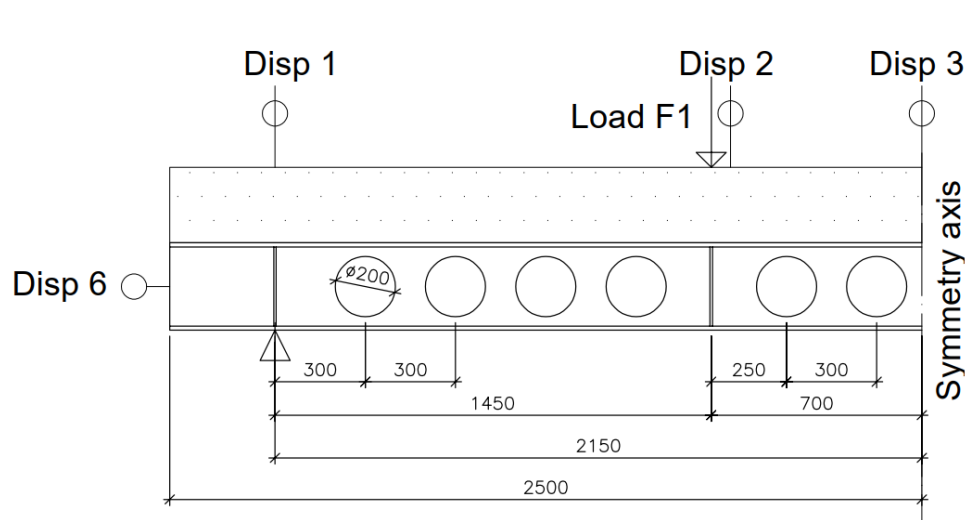

(a)

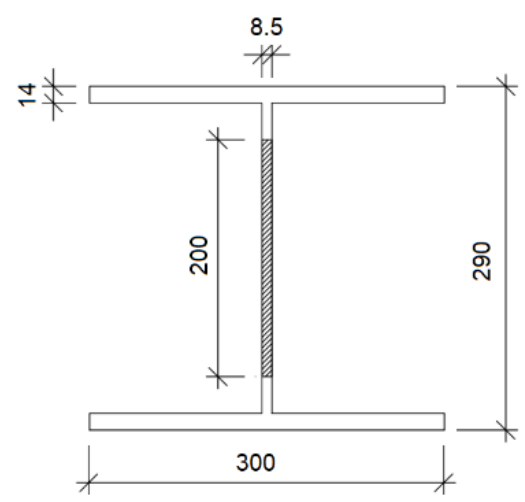

(b)

Fig. 3. Schematic view of (a) half the test specimen and (b) the elevation (all dimensions are in $\mathrm{mm}$ ) 


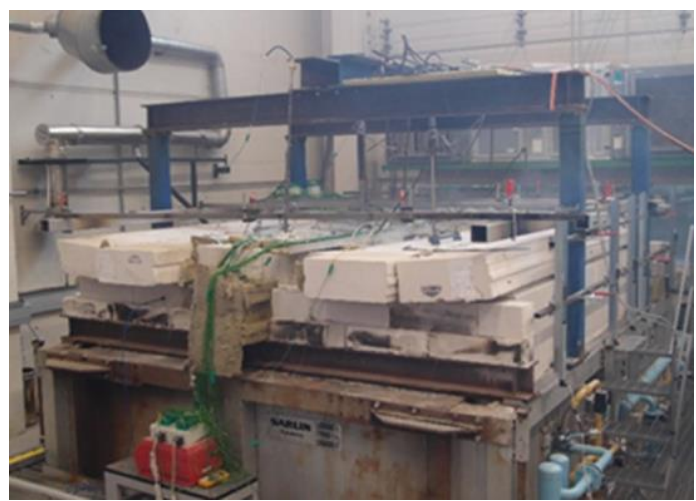

(a)

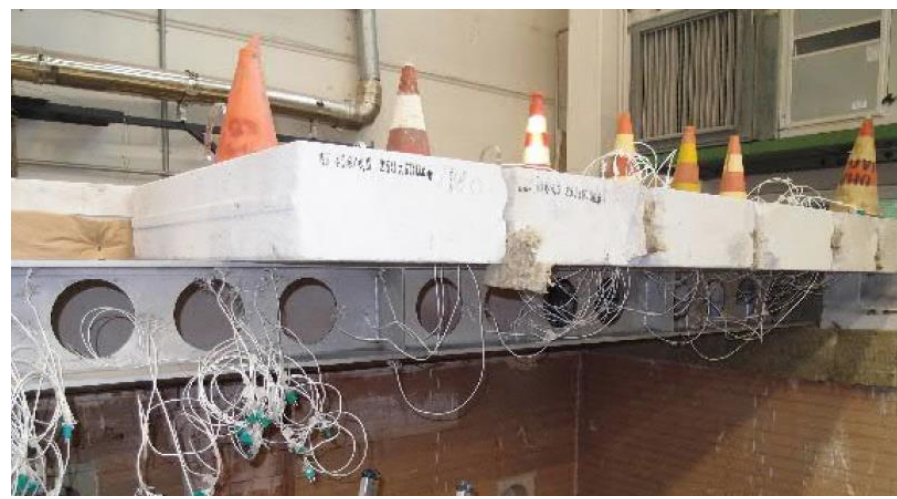

(b)

Fig. 4. Images from the test including (a) the loading arrangement above the furnace, and (b) the specimen before testing, including the concrete blocks on the top flange. 

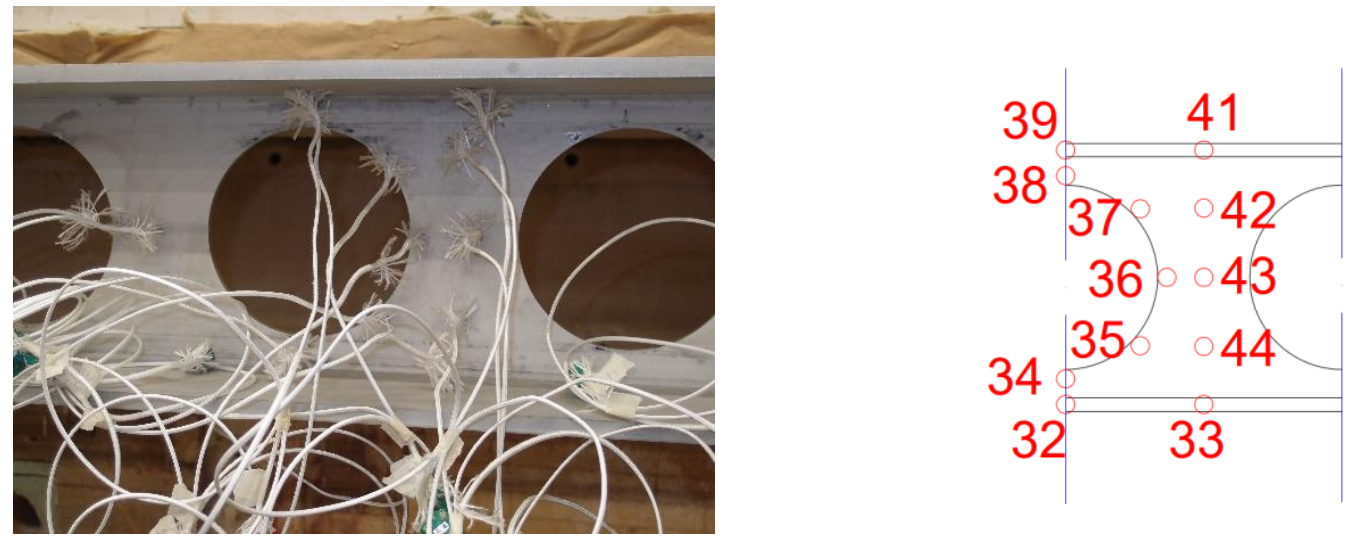

Fig. 5. Locations of the thermocouples in the beam at the mid-span. 


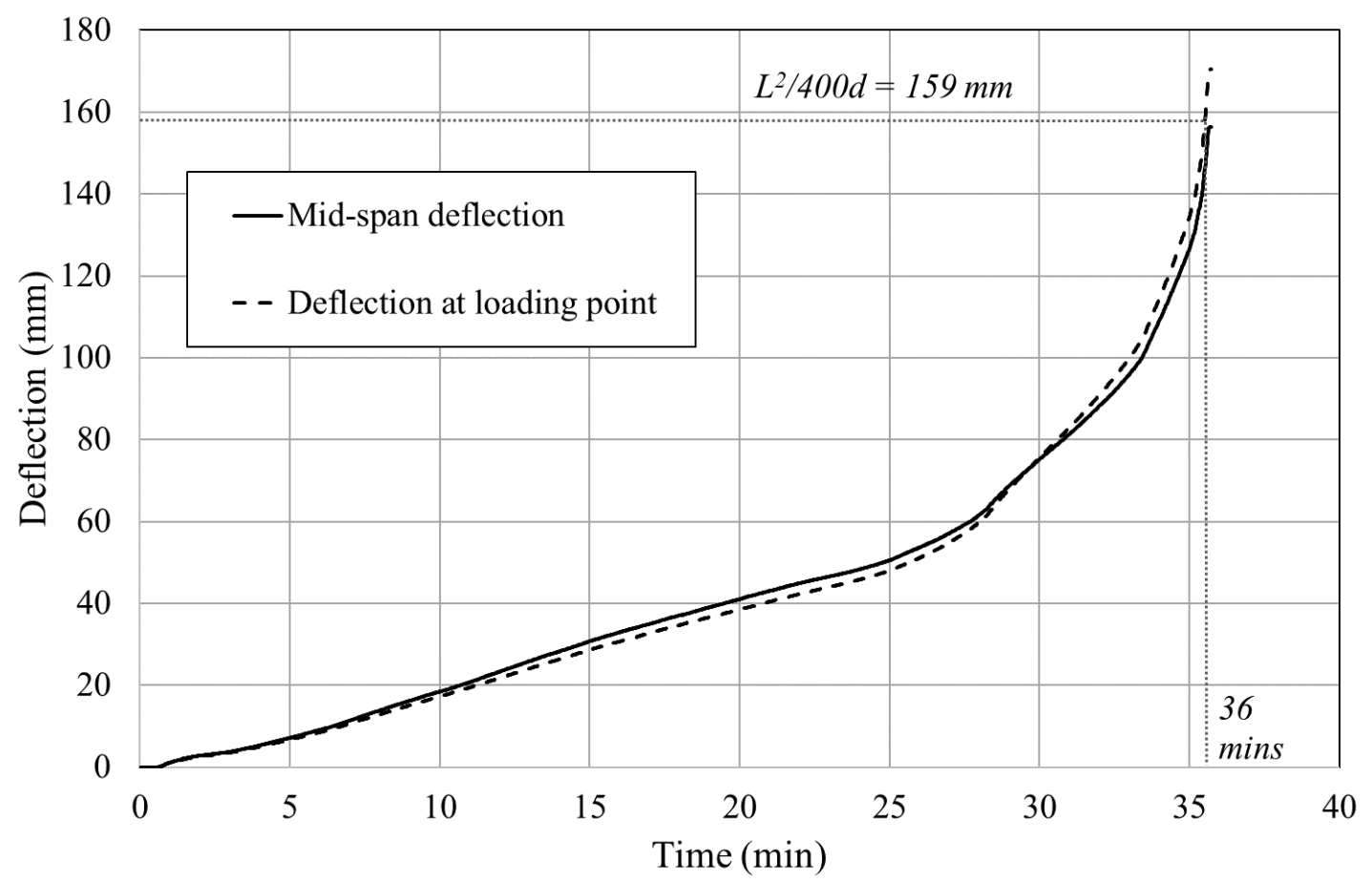

(a)

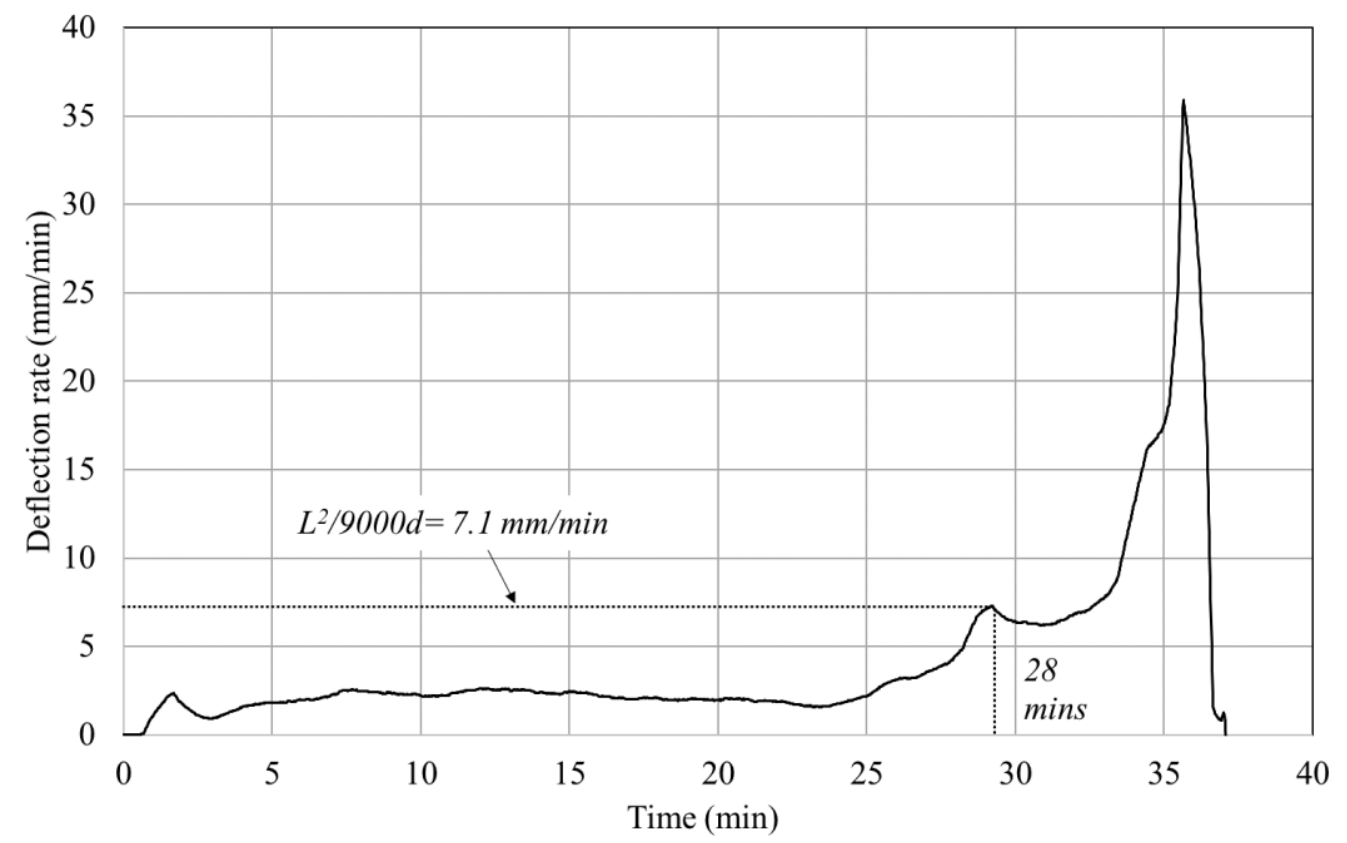

(b)

Fig. 6. Test results in terms of (a) vertical beam deflections versus time and (b) rate of midspan deflection with time. 


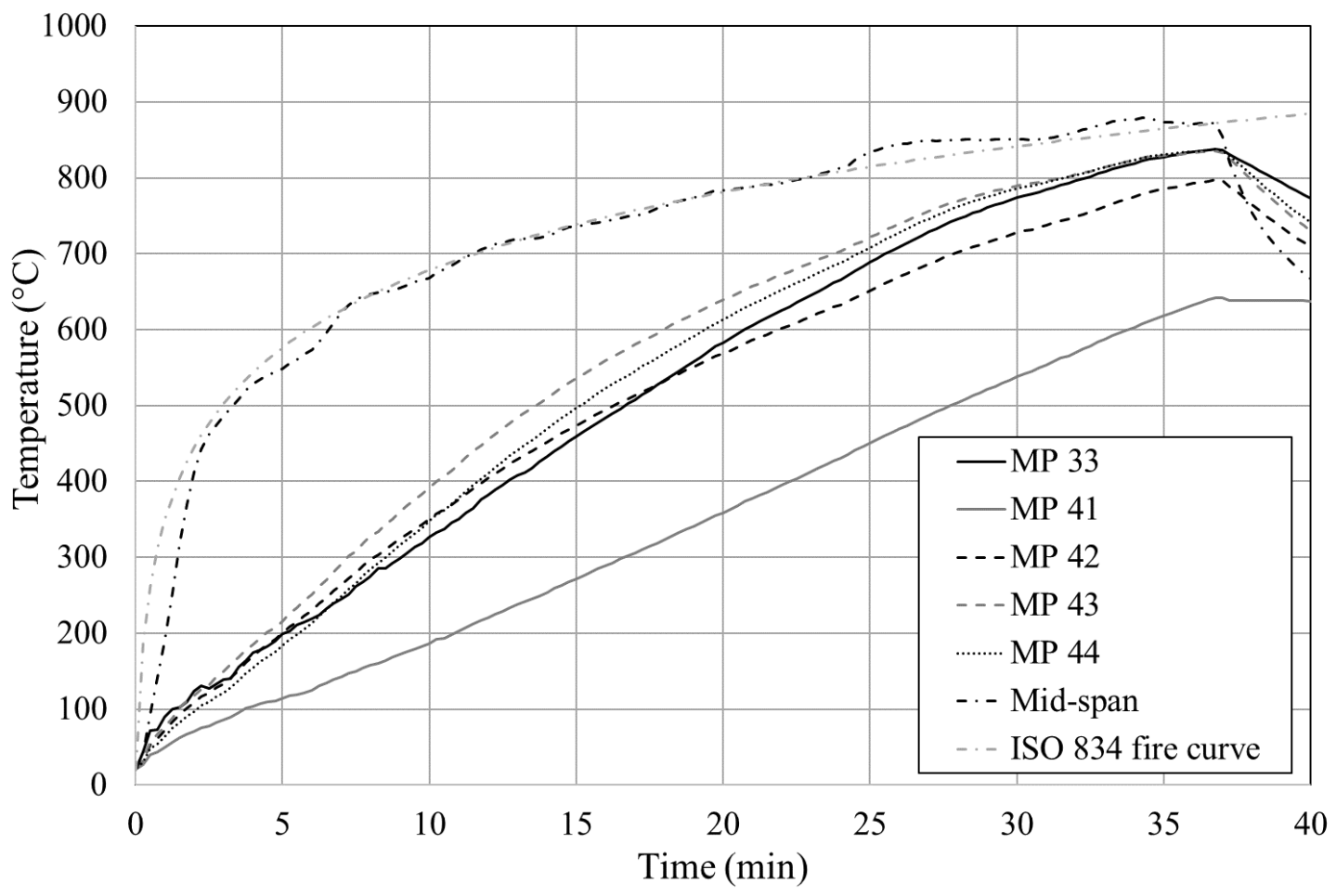

(a)

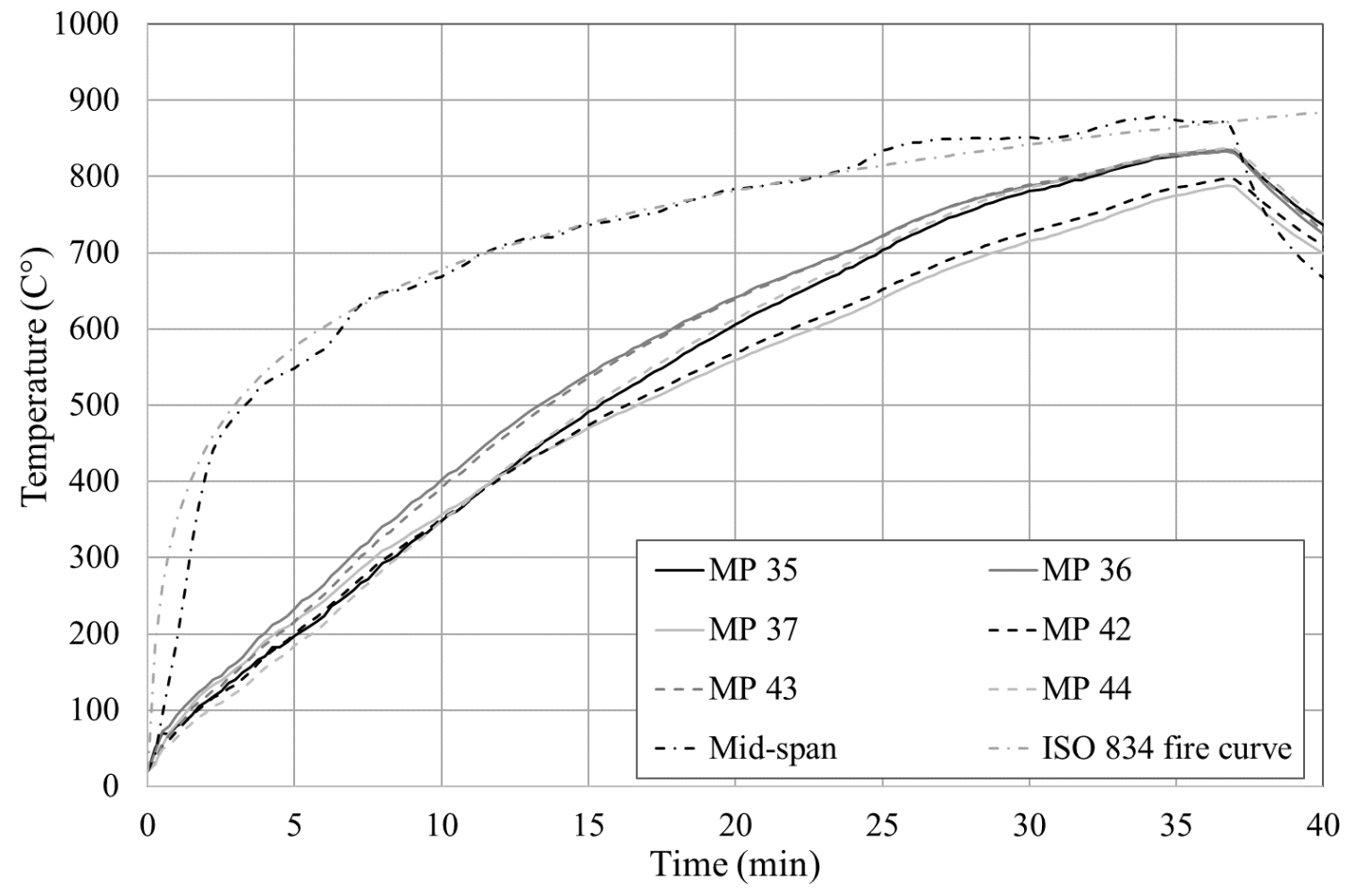

(b)

Fig. 7. Development of the stainless steel temperatures at mid-span (a) over the beam crosssection and (b) in the web. 


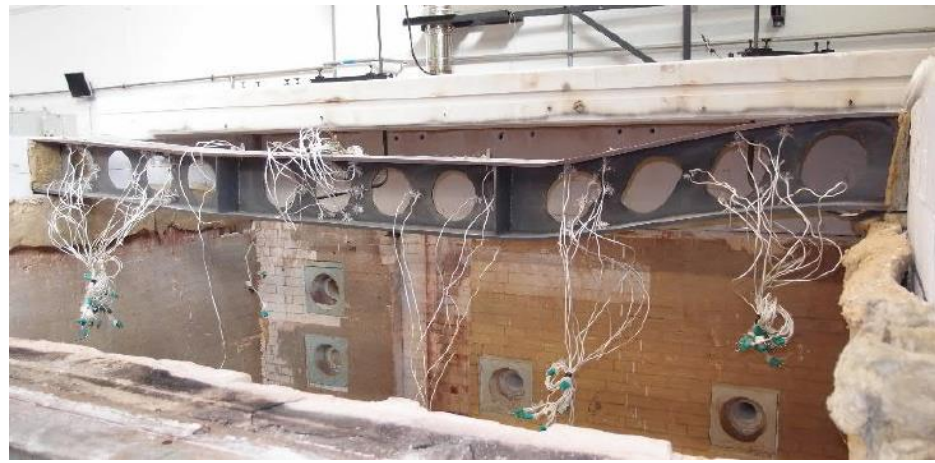

(a)

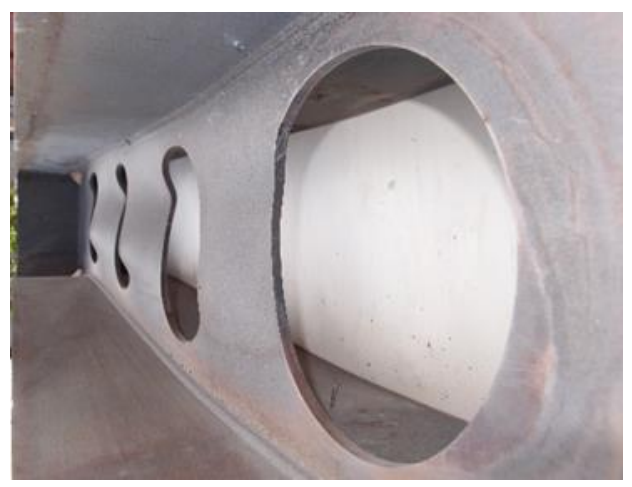

(b)

Fig. 8. Images from the test specimen after testing including views of (a) the full member and (b) web-post buckling. 


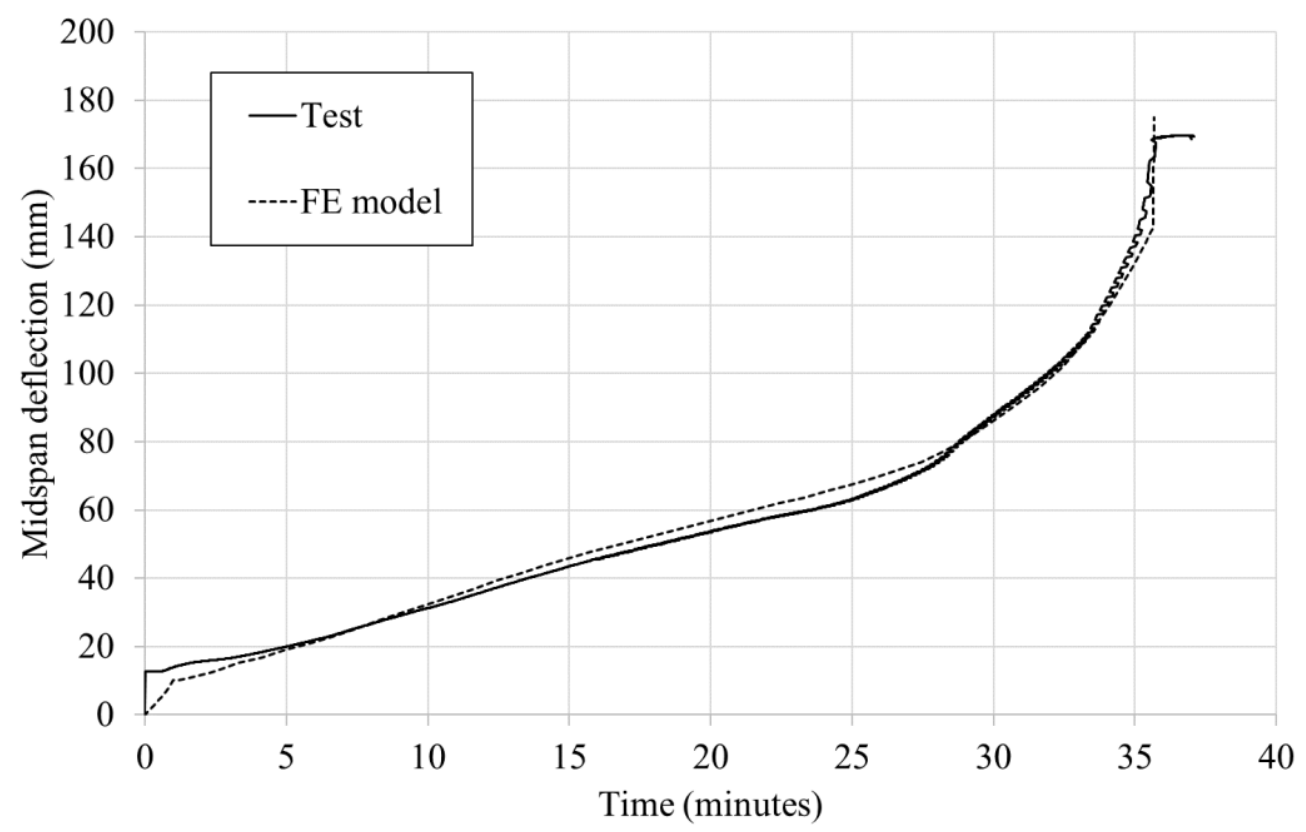

(a)

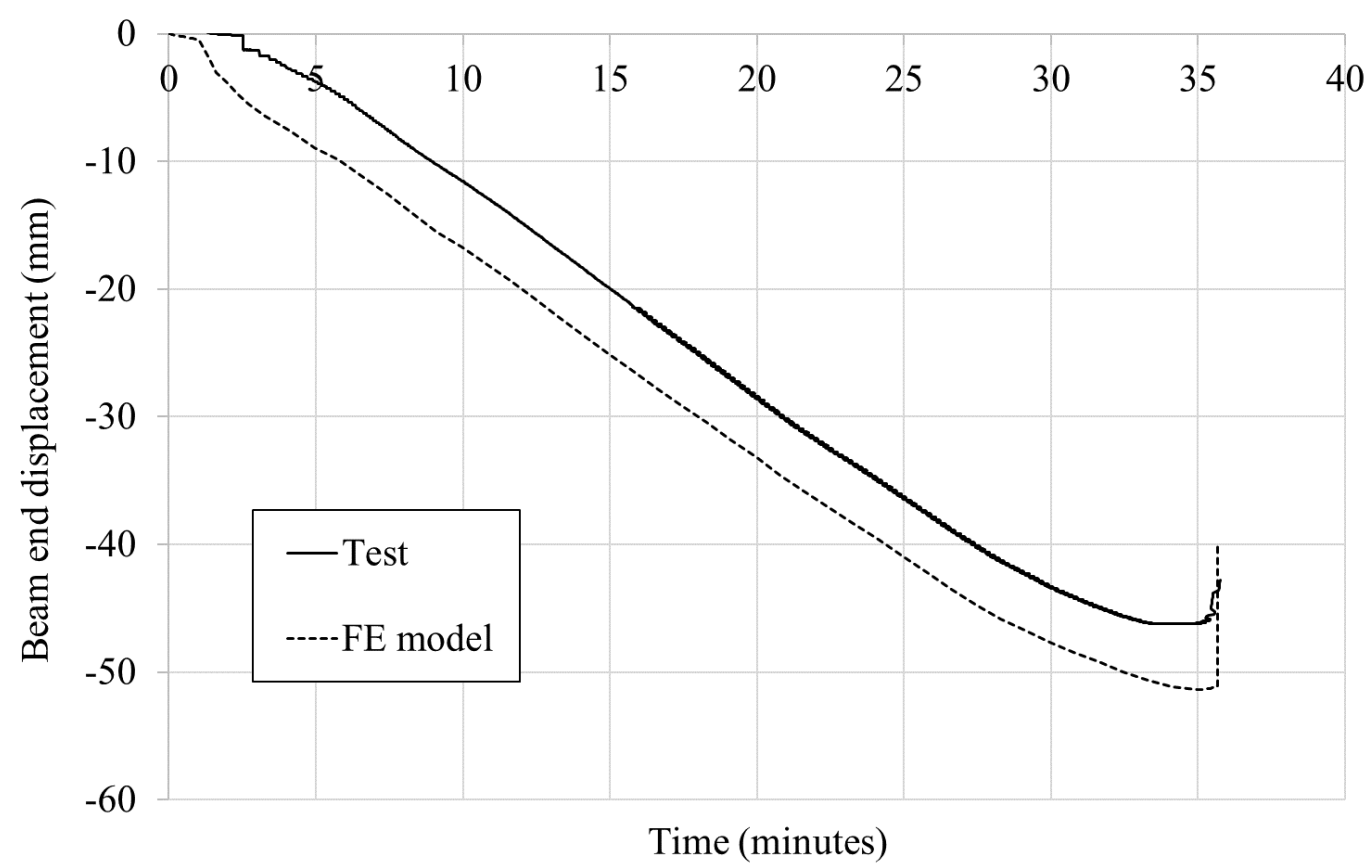

(b)

Fig. 9. Comparison between the experimental results and FE simulations for (a) deflection versus time and (b) horizontal beam end displacements versus time 


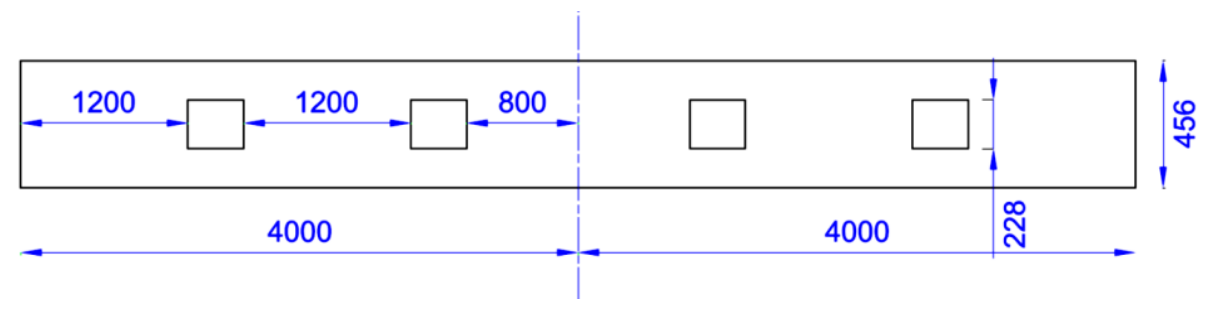

(a)

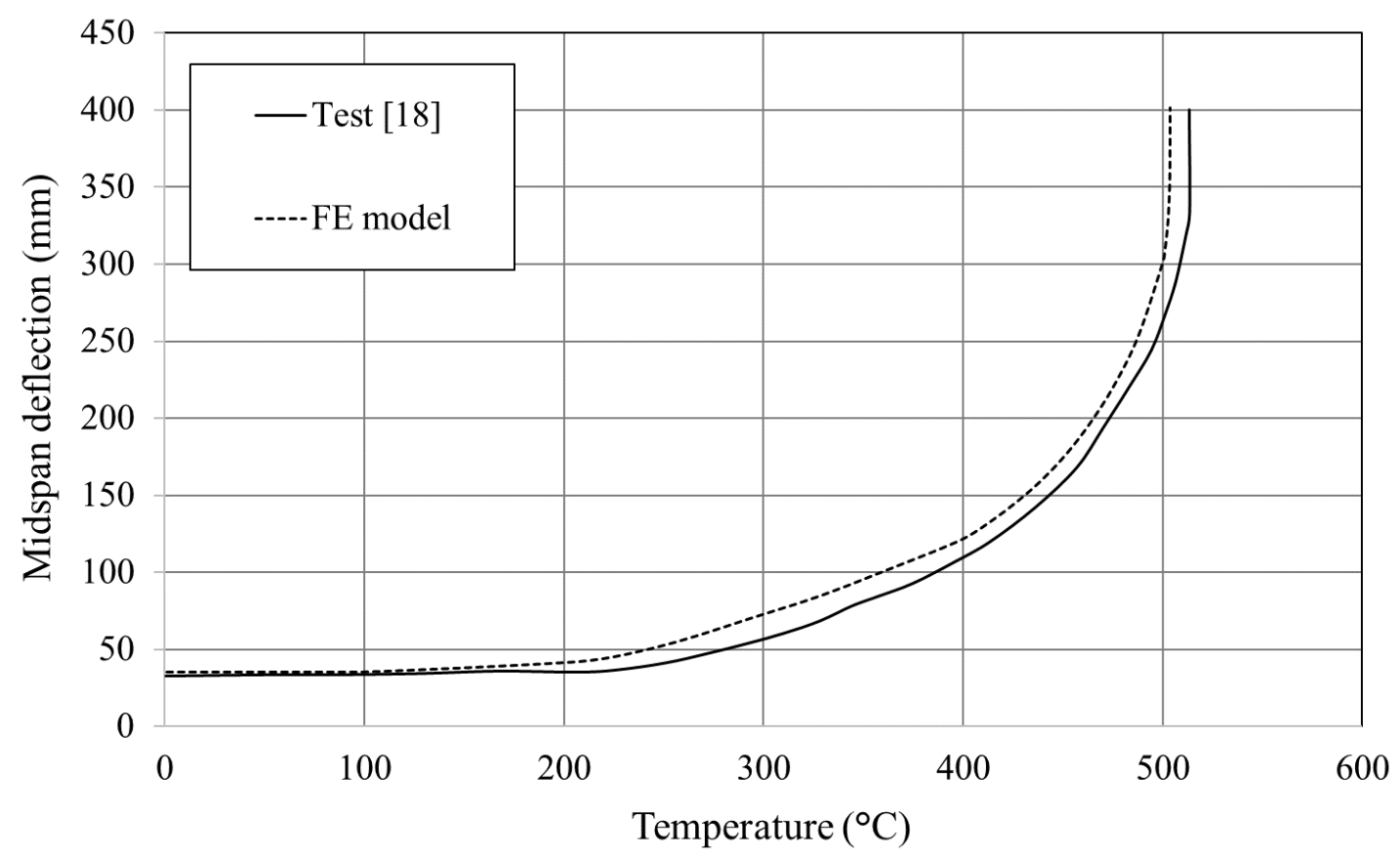

(b)

Fig. 10. Validation of the cellular beam experiment conducted elsewhere [18] illustrating (a) the beam arrangement (all units in $\mathrm{mm}$ ) and (b) the mid-span deflection versus temperature 


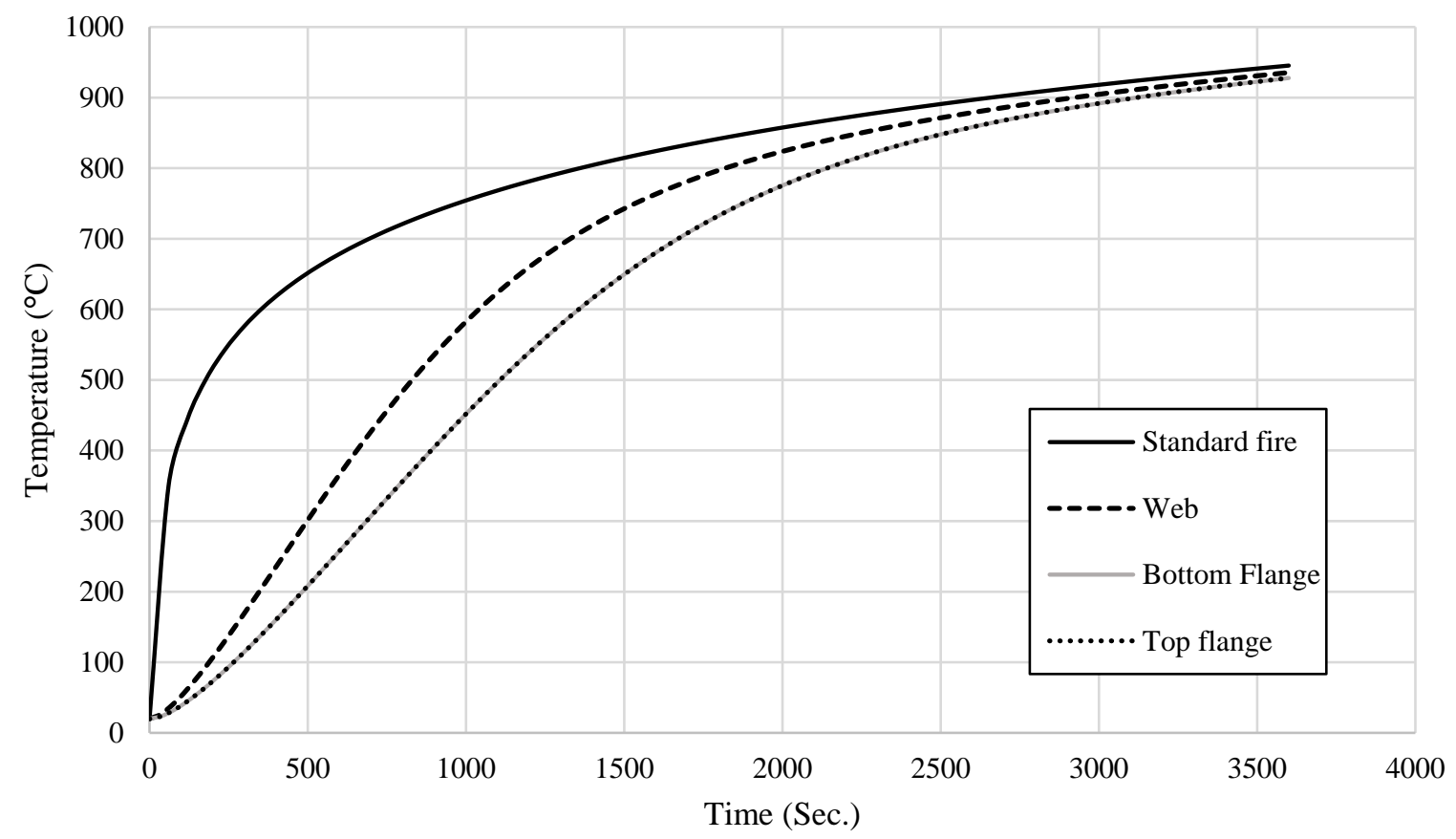

Fig. 11 Temperature history at various location for austenitic steel beam from heat transfer analysis 


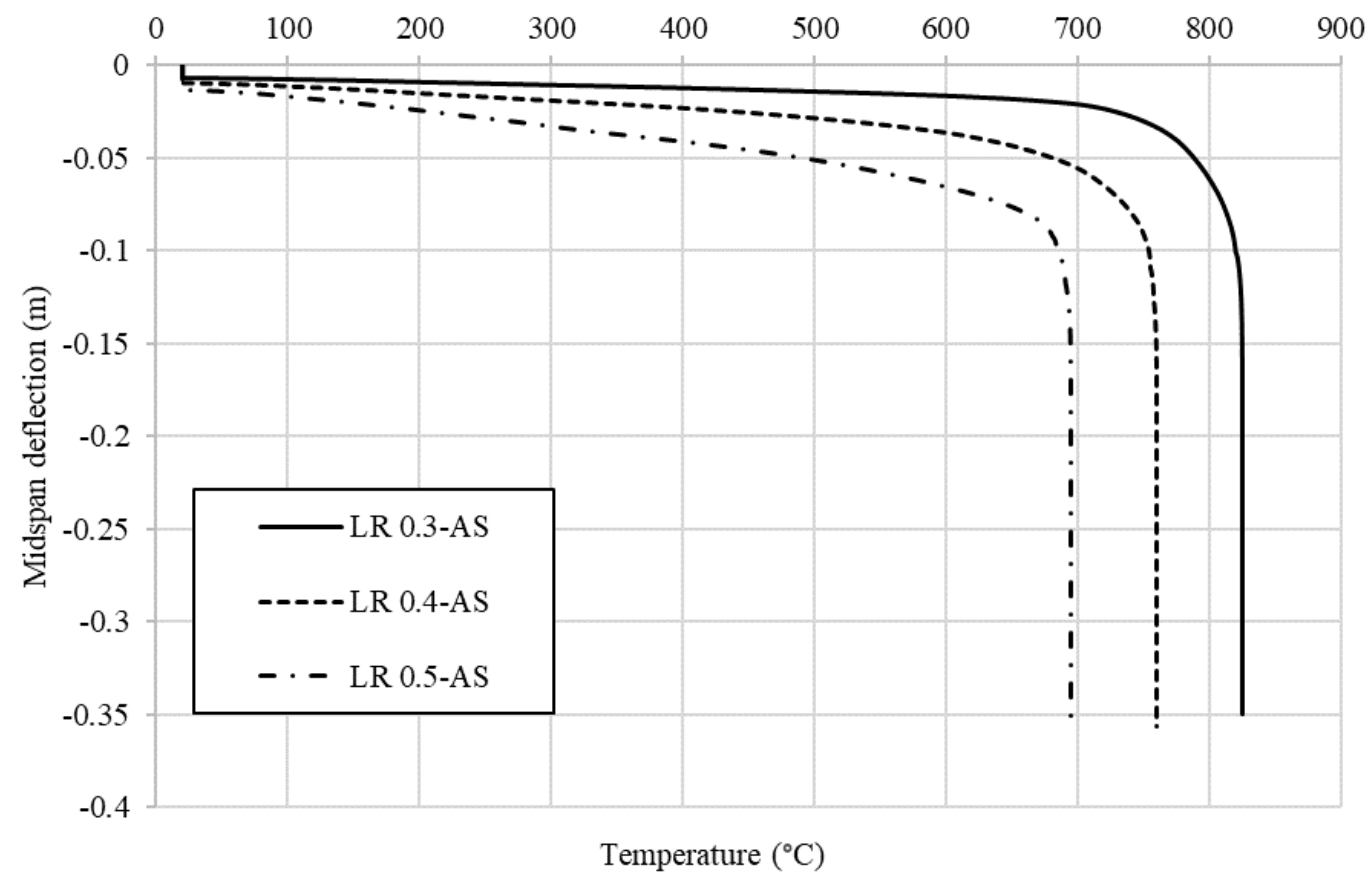

Fig. 12 Mid-span deflection versus bottom flange temperature for cellular beams subjected to different levels of load ratio and made from austenitic stainless steel 


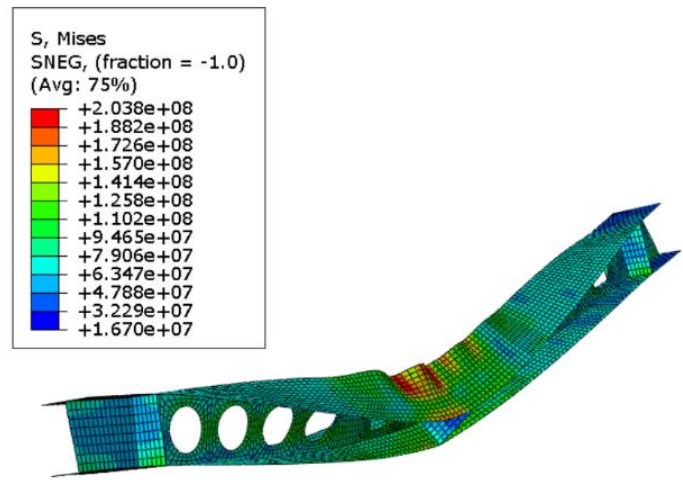

(a)

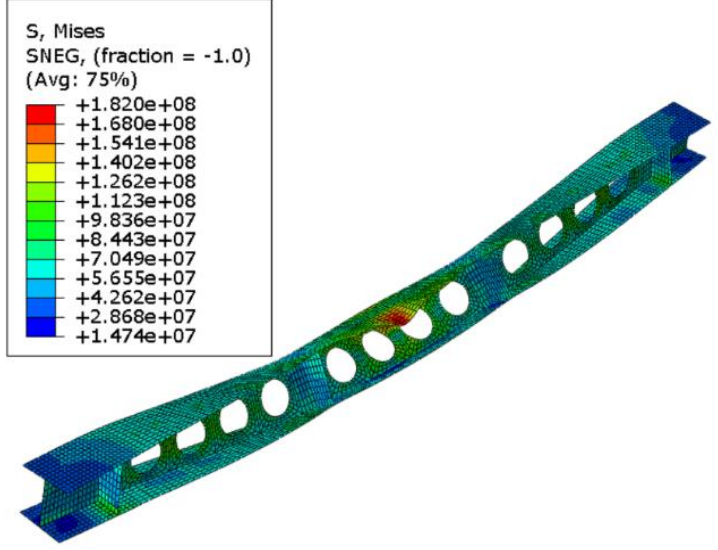

(c)

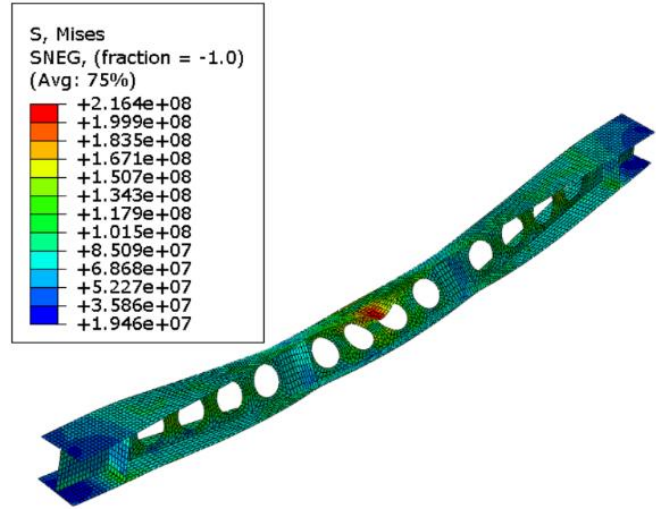

(e)

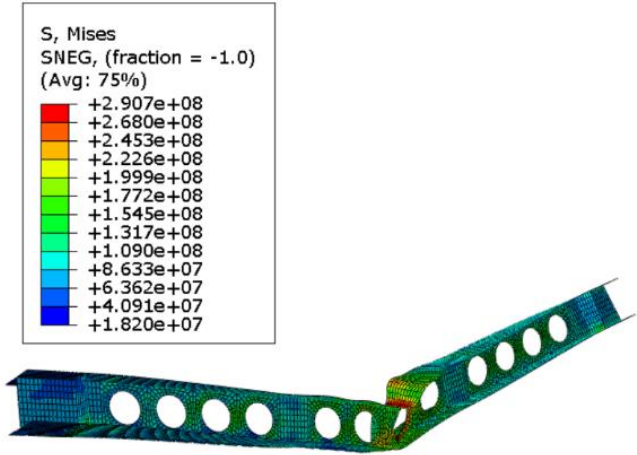

(b)

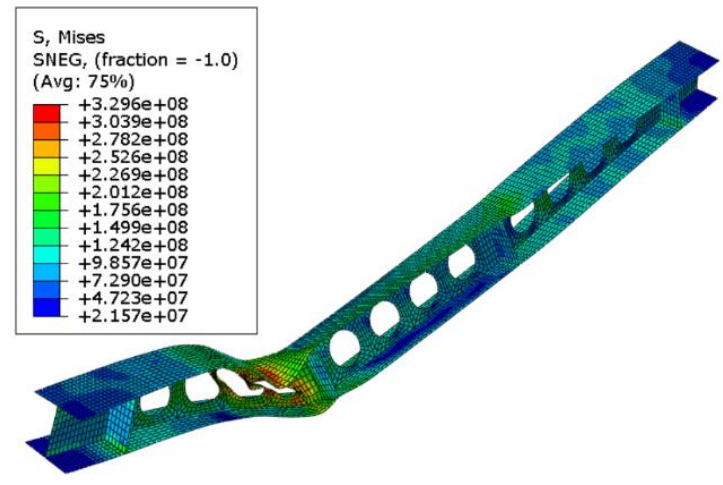

(d)

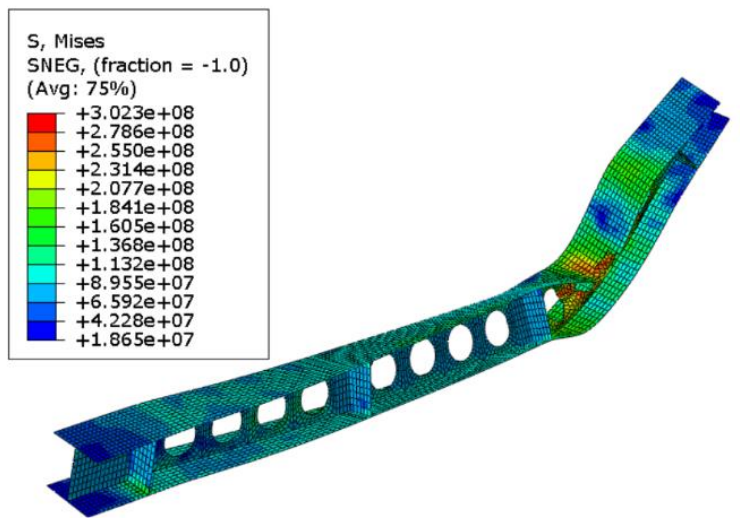

(f)

Fig. 13 Images from the FE model illustrating the failure modes for austenitic stainless steel cellular beams with (a) LR of 0.3 and 3 point loading (b) LR of 0.5 and 3 point loading, (c) LR of 0.3 and 4 point loading, (d) LR of 0.5 and 4 point loading, (e) LR of 0.3 and UDL, and (f) LR of 0.5 and UDL 


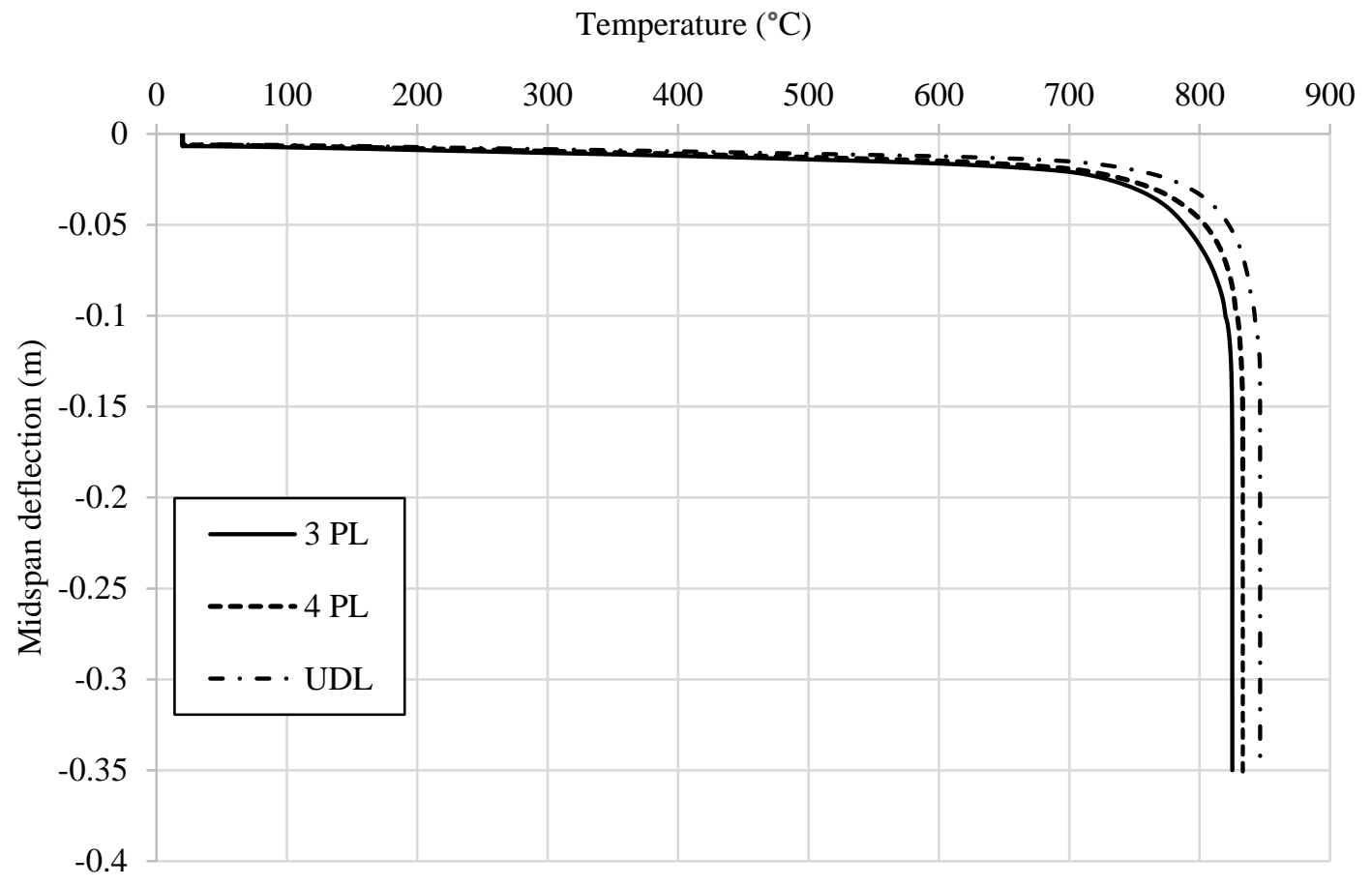

Fig. 14 Mid-span deflection versus bottom flange temperature for austenitic stainless steel cellular beams subjected to different loading types 


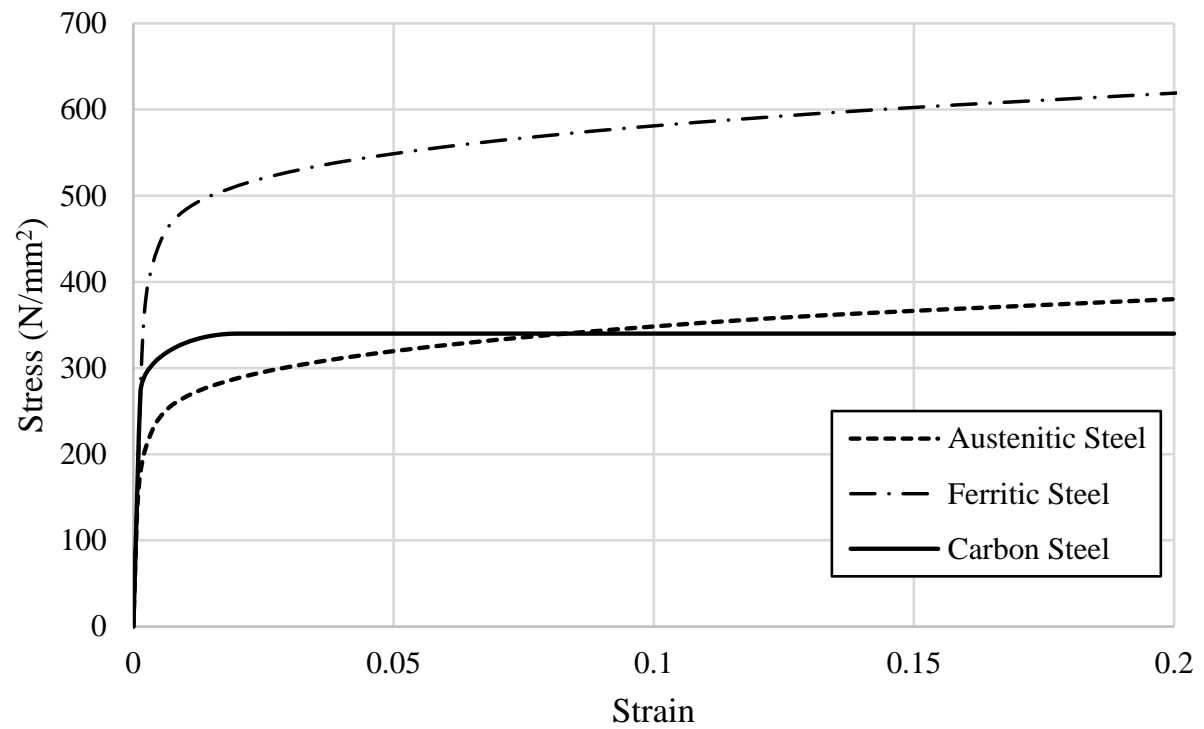

Fig. 15 Stress-strain response for the different materials included in the study 


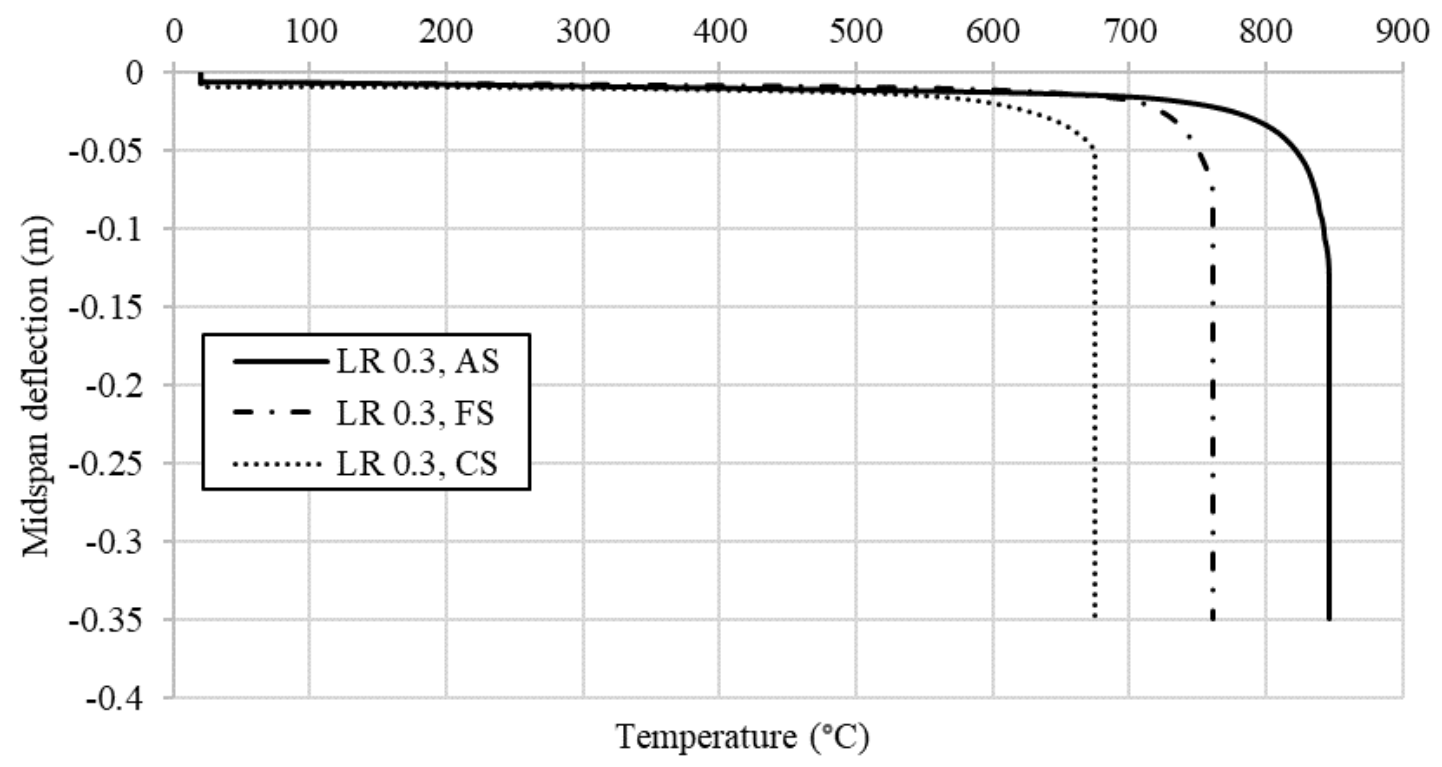

(a)

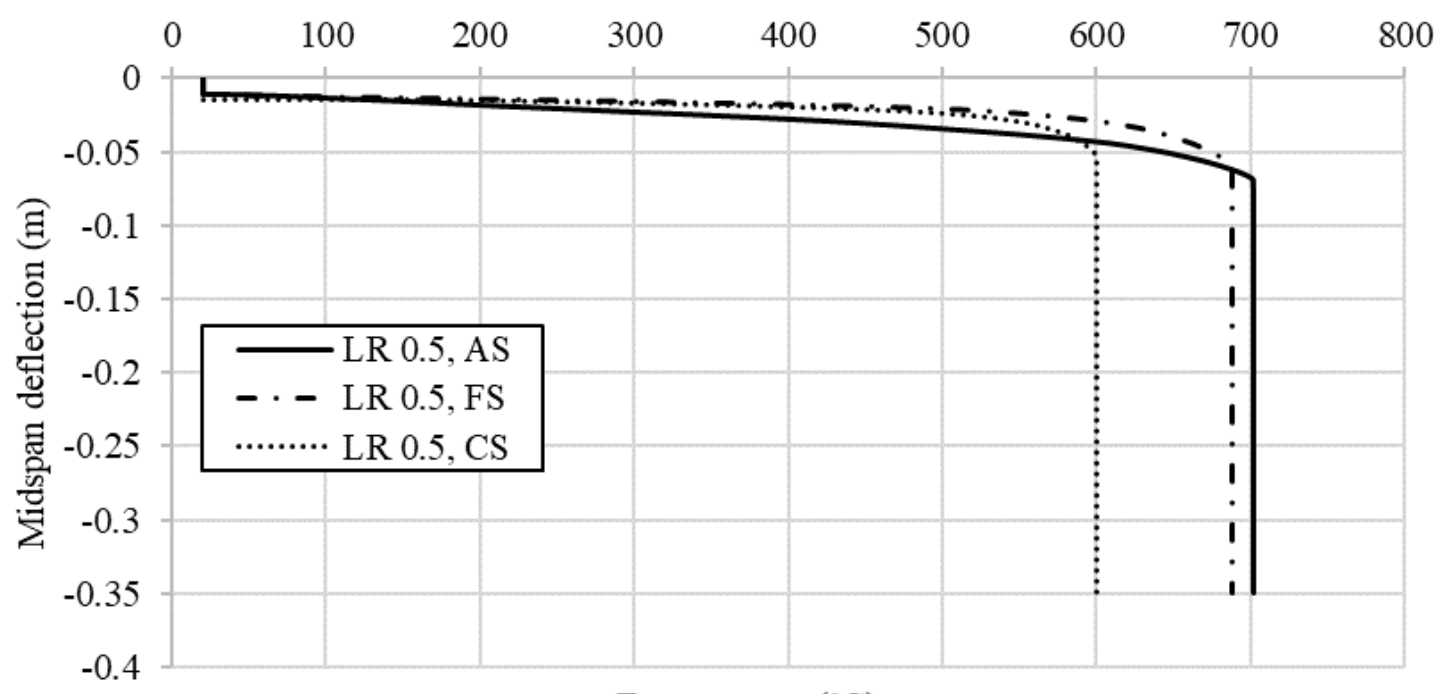

Temperature $\left({ }^{\circ} \mathrm{C}\right)$

(b)

Fig. 16 Comparison for cellular beams made from different materials for (a) $L R=0.3$ and (b) $\mathrm{LR}=0.5$ 